\title{
Social TV, Advertising, and Sales: Are Social Shows Good for Advertisers?
}

\author{
Beth L. Fossen ${ }^{1}$ \\ David A. Schweidel ${ }^{2}$
}

October 2018

Published in Marketing Science

${ }^{1}$ Assistant Professor of Marketing, Kelley School of Business, Indiana University. Address: 1309 East Tenth Street, Bloomington, Indiana 47405, Email: bfosssen@indiana.edu

${ }^{2}$ Professor of Marketing, Goizueta Business School, Emory University. Address: 1300 Clifton Road Northeast, Atlanta, Georgia 30322, Email: dschweidel@emory.edu

The authors thank comScore, Inc. for providing part of the data and the Goizueta Business School research support for providing the funds to acquire and build the dataset in this research. The authors also thank seminar participants at Washington University, the 2016 INFORMS Annual Meeting Conference, and the 2016 INFORMS Marketing Science Conference for their helpful suggestions and comments. 


\title{
Social TV, Advertising, and Sales: Are Social Shows Good for Advertisers?
}

\begin{abstract}
Television viewers are increasingly engaging in media-multitasking while watching programming. One prevalent multiscreen activity is the simultaneous consumption of television alongside social media chatter about the programming, an activity referred to as "social TV." While online interactions with programming can result in a more engaged and committed audience, social TV activities may distract media multitaskers from advertisements. These competing outcomes of social TV raise the question: are programs with high online social TV activity, so called "social shows," good for advertisers?

In this research, we empirically examine this question by exploring the relationship among television advertising, social TV, online traffic, and online sales. Specifically, we investigate how the volume of program-related online chatter is related to online shopping behavior at retailers that advertise during the programs. We find that advertisements that air in programs with more social TV activity see increased ad responsiveness in terms of subsequent online shopping behavior. This result varies with the mood of the advertisement, with more affective advertisements - in particular, funny and emotional advertisements - seeing the largest increases in online shopping activity. Our results shed light on how advertisers can encourage online shopping activity on their websites in the age of multi-screen consumers.
\end{abstract}

Keywords: social TV, television, advertising, social media, online word-of-mouth 


\section{Introduction}

Multi-screen activity by television viewers is on the rise with an estimated $80 \%$ of U.S. television viewers simultaneously using another device while watching television (IAB 2015; Nielsen 2014). One of the most prevalent multi-screen activities is social TV, which is the joint viewing of television programming alongside the consumption and/or production of programrelated social media chatter (Benton and Hill 2012; Fossen and Schweidel 2017). Nearly $40 \%$ of multi-screeners in the U.S. engage in social TV activity (IAB 2015).

The rapid growth of social TV has raised questions for advertisers. On the one hand, social TV may benefit advertisers. Participation in online chatter may engage viewers, making them more tuned-in to the show, which in turn may improve the effectiveness of subsequent ads (Flomenbaum 2016; Nielsen 2015a). Research on media context effects has shown that increased show involvement can improve attitudes and purchase intent of advertised brands (e.g., Feltham and Arnold 1994; Kilger and Romer 2007; Norris and Colman 1993) and reduce ad avoidance (Teixeira et al. 2010). The positive effects of program involvement on ad response are thought to result from a halo effect, with the increased interest in the show carrying over to the processing of the ads (e.g., Feltham and Arnold 1994; Schweidel et al. 2014; Wang and Calder 2009).

On the other hand, social TV may distract viewers from watching and processing ads. As a result, "social shows," those programs with high levels of social TV activity, may be less attractive to advertisers. Indeed, research has found that high levels of show involvement can hurt ad recall (Norris and Colman 1993; Tavassoli et al. 1995). Fossen and Schweidel (2017) also find evidence to suggest that viewers that discuss shows online may be doing so at the expense of engaging with advertised brands online. Recent studies have also found that online activities and television viewing may be substitute activities (Hinz et al. 2016; Seiler et al. 2017). 
In this research, we empirically examine these contrasting theories on the link between online program engagement - as inferred from social TV activity - and ad effectiveness by presenting the first examination of the relationship among television advertising, social TV, online traffic, and online sales. We explore two research questions. First, are social shows beneficial for advertisers? To explore this, we examine how online program engagement relates to changes in online traffic and purchases for retailers following television ads. We consider two measures of social TV and allow their relationship with ad response to vary across ad characteristics. Examining this question allows us to extend (1) research on cross-media effects that has yet to consider the joint relationship among television advertising, online word-of-mouth (WOM), and online shopping and (2) work on media context effects that has not explored media multitasking. Second, how can television advertising increase online shopping? We investigate how retailers can use ad design and media buying strategies to encourage online traffic and sales following television ads. We extend research on the relationship between television advertising and online shopping (Liaukonyte et al. 2015) by accounting for social TV behavior. Overall, our investigation of these research questions allows us to (1) examine how social TV activity relates to changes in viewers' responses to television ads in terms of traffic to and purchases on advertisers' websites and (2) shed light on how advertisers can use ad design and media buying strategies to encourage online shopping activity in the age of multi-screen consumers.

We build a multi-source data set that includes online traffic and sales on retailers' websites, primetime television advertising for the retailers, social media chatter mentioning the programs in which the ads air or the retailers, and ad and program characteristics. Our data include over 1,600 ad instances for five retailers that advertise on 83 programs during the fall 2013 television season. We jointly model the traffic and sales on a retailer's website following an 
ad's airing as a function of social TV activity and ad and program characteristics using a hierarchical Bayesian regression. We assess the relationship between social TV activity about the program and online shopping by considering two measures of online program engagement: the volume of program chatter and change in program chatter immediately prior to an ad's airing.

We find a significant relationship between online program chatter and online shopping following advertisements, with these effects varying with the mood of the ad. Emotional ads spur the largest increases in web traffic when they air in shows with higher volumes of program chatter. Across both measures of online program engagement, we find that ads spur more online purchases when they air in more social shows, with funny ads spurring the largest increases in sales when they air in more social shows and with active and informational ads generating the smallest increases in sales. More affective ads - in particular, those with an emotional or funny mood - may be more successful in social shows because such ads effectively recapture viewers' attention from the program and allow for the engaged processing of the program to spillover to ad processing (e.g., Eisend 2009; Olney et al. 1991; Sternthal and Craig 1973; Zillmann et al. 1980). Overall, our results suggest that social shows benefit advertisers, with advertisers airing affective ads seeing the largest increases in subsequent online shopping activity.

The remainder of this research is organized as follows. We next review work on program engagement and media context effects to explore what influence social shows may have on ad effectiveness. We then discuss the data and the modeling approach. We present our results and conclude with a discussion of implications of our research for retailers and television networks as well as opportunities for future research on media context effects and cross-media effects.

\section{Television Program Engagement and Media Context Effects on Advertisements}


Are social shows good for advertisers? Research has not yet explored the relationship between online program engagement and sales of advertised brands. However, past work has established that television content can impact online behaviors (e.g., Fossen and Schweidel 2017; Joo et al. 2014; Lewis and Reiley 2013; Liaukonyte et al. 2015) and has explored the impact of other measures of show involvement on ad effectiveness. This research also has argued that online chatter reflects broader trends in viewer engagement (Godes and Mayzlin 2004). Industry studies also have begun to explore how social TV activity correlates with viewers' attention and ad response (e.g., Nielsen 2015a; Nielsen 2015b). We use the insights from these works to discuss why social shows may be either good or bad for advertisers. While our intent is not to test a particular behavioral theory, we use the following discussion to motivate our empirical analysis.

\subsection{Why Social Shows May Be Good for Advertisers}

Research on media context and cross-media effects suggest four key reasons why programs with high online engagement may benefit advertisers. First, participation in online chatter about a program may indicate that viewers are engaged with the program, which enhances opportunities to process ads. Nielsen (2015a) finds a positive correlation between Tweets about programs and neurological measures of engagement (attention, memory, and emotional arousal) for the program's general audiences. Thus, increases in online engagement may correlate with increases in neurological engagement that improve viewers' opportunities to process ads. Research on media context effects supports these findings, arguing that heightened program involvement can increase viewers' cognitive arousal and attention, which enhances viewers' opportunities to process ads (e.g., Celsi and Olson 1988; Dahlén 2005; Lord and Burnkrant 1993; Maclnnis et al. 1991). Studies also show that increases in viewer attention, processing effort, and/or involvement with programs relate to better ad recall (Singh and Hitchon 1989), improved ad attitudes 
(Feltham and Arnold 1994; Murry et al. 1992), reduced ad skipping (Teixeira et al. 2010;

Woltman Elpers et al. 2003), and increased purchase intent (Feltham and Arnold 1994; Kilger and Romer 2007; Norris and Colman 1993). The effects of increased program involvement on ad effectiveness are argued to be driven by a halo effect, with increased program interest carrying over to ad processing (e.g., Dahlén 2005; Schweidel et al. 2014; Wang and Calder 2009).

Second, online program engagement may encourage a committed viewing audience. Shows with high online chatter have more viewers who watch multiple episodes, watch live, and watch without changing the channel during ads (Nielsen 2015b; Russell 2012), all of which are important to advertisers (Lynch 2015). Third, social shows may benefit advertisers because media multitasking during television viewing can decrease the ability to counterargue or resist persuasion attempts, thereby increasing ad effectiveness (e.g., Jeong and Hwang 2012; Kazakova et al. 2016). Lastly, social TV may be good for advertisers because it can increase production and consumption of brand-related earned media. Viewers who converse about programs may also discuss ads online, an activity that increases earned media for the advertised brand and provides advertisers with a real-time gauge of ad effectiveness (Fossen and Schweidel 2017). Viewers engaged on social media during shows also may be exposed to and more attentive to consumption-oriented earned media, which can prime a shopping mindset (Zhang et al. 2017).

\subsection{Why Social Shows May Be Bad for Advertisers}

While several studies present evidence that online program engagement is good for advertisers, other work suggests that it may be detrimental to ad effectiveness. The same factors that enhance a viewer's opportunity to process ads - like an engaging program - may reduce her motivation or ability to process ads (MacInnis et al. 1991). Indeed, higher levels of program engagement can distract viewers from ad information by lowering attentional or motivational capacity to process 
ads (e.g., Feltham and Arnold 1994; Hinz et al. 2016; Kazakova et al. 2016; Lord and Burnkrant 1993; Tavassoli et al. 1995; Teixeira et al. 2014; Sternthal and Craig 1973). Increased program engagement also can enhance perceptions that ads are intrusions (Schweidel and Moe 2016). The negative effects of high program involvement can damage ad recall (Norris and Colman 1993; Pavelchak et al. 1988; Tavassoli et al. 1995), ad attitudes (Tavassoli et al. 1995), and ad persuasiveness (Teixeira et al. 2014). However, Tavassoli et al. (1995), Pavelchak et al. (1988), and Teixeira et al. (2014) only find these effects at very high levels of show involvement.

Consistent with the idea that social shows may be bad for advertisers, recent work has found that television viewing and online activity may be substitute behaviors. Fossen and Schweidel (2017) find evidence that viewer online engagement with programs may occur at the expense of online engagement with advertised brands. Hinz et al. (2016) suggest that major television events can reduce online activity on bidding websites. Finally, Seiler et al. (2017) find that the inability of viewers to engage in social TV activity during programs does not impact viewing, suggesting that these may not be complementary activities.

\subsection{The Role of Mood of the Advertisement}

As increased program involvement may enhance the opportunity to process ads while simultaneously reducing the motivation or ability to process ads, we anticipate that television ads that successfully increase viewer attention or motivation to process ads will be more effective in social shows. Research has shown that specific ad characteristics can increase viewer attention and motivation to process ad information. Notably, among these are humor appeals (e.g., Eisend 2009; MacInnis et al. 1991; Sternthal and Craig 1973; Zillmann et al. 1980). In contrast, informational ads can have the opposite effect (Woltman Elpers et al. 2003). Research has also found that entertaining and affective ads, compared to informational and rational ads, gain more 
attention from viewers and reduce ad skipping (Olney et al. 1991; Woltman Elpers et al. 2003; Yoo and MacInnis 2005). When motivation to process an ad is low, a situation that may occur at high levels of program involvement, informational and rational ads may be even less effective, while ads with a positive mood may be more effective (MacInnis et al. 2002). Rational ads may be less effective when program entertainment is high because these ads deviate from the hedonic viewing experience, reducing viewers' motivation and ability to process ad information (Woltman Elpers et al. 2003). Overall, these works suggest that the benefit of social shows for advertisers may depend on the mood of the advertisement, with affective ads expecting improved ad effectiveness relative to rational ads when online engagement with the program is high.

\subsection{Social TV and Online Shopping}

Prior work has not examined what impact program involvement will have on ad response when (1) program engagement occurs online, which involves some viewers' media multitasking, and (2) ad response is studied in terms of actual sales rather than other ad effectiveness measures such as recall and purchase intent. The two closest works to this study, Liaukonyte et al. (2015) and Fossen and Schweidel (2017), do not address these questions. We extend Liaukonyte et al. (2015)'s study of television advertising's impact on online shopping by considering how online program engagement may effect this relationship. We build on Fossen and Schweidel (2017)'s analysis of social TV by examining how program chatter impacts ad response beyond changes in online brand WOM by considering its relationship with online sales.

We treat the investigation of the relationship between social TV and online shopping and the assessment of whether social shows are good for advertisers as empirical questions. We consider two measures of online program engagement: (1) the volume of program chatter in an episode leading up to an ad's airing and (2) the change in program chatter in the minute prior to 
an ad's airing. Following prior research, we allow the effects of online program engagement to be non-linear (e.g., Tavassoli et al. 1995). We consider these two measures because both the volume and the temporal variation in online WOM have been linked to sales (Gelper et al. 2018; Xiong and Bharadwaj 2014). A sudden spike in program-related online chatter also indicates an increase in media multitasking, an activity that can create attention-diminishing task interference (Brasel and Gips 2011; Kazakova et al. 2016). As such, we may see different effects of online program engagement on ad response when considering the volume of program mentions versus the change in program mentions in the minute before the ad airs. Following previous work that suggests that program involvement may moderate the impact of ad mood on ad response, we also explore interactions between the two measures of online program engagement and ad mood.

\section{Data Description}

\subsection{Online Shopping Data}

We collected data on online shopping behavior from comScore, Inc.'s Web Behavior Database ${ }^{1}$. These data contain browsing activity for a panel of 100,000 active U.S. internet users and include machine- and minute-level data on traffic to and purchases on a given website. This panel is a random sample of U.S. users from more than two million global panelists that have given comScore explicit permission to track their online browsing and buying. Our data include online traffic and purchases from this panel at the websites of five large, national retailers ${ }^{2}$. Each of these retailers - or the retailer's parent company in one case - appeared on the 2013 Fortune 500 list and netted at least $\$ 10$ billion in sales in the 2013 fiscal year. We track new sessions and

\footnotetext{
${ }^{1}$ Prior work in marketing on online shopping has used comScore data (e.g., Johnson et al. 2004; Liaukonyte et al. 2015; Montgomery et al. 2004).

${ }^{2}$ Due to our agreement with comScore, we cannot disclose the names of the retailers.
} 
purchases on the retailers' websites and on the websites mentioned in the retailers'

advertisements during the fall 2013 television season (September-December 2013) . $^{3}$

\subsection{Advertising Data}

Advertising data are collected for the retailers from Kantar Media's Stradegy database. These data include national, primetime, broadcast (ABC, CBS, CW, FOX, and NBC) advertisements on the initial airing of recurring programs ${ }^{4}$ from the fall 2013 television season. The retailers advertise a range of products including apparel accessories, computers and accessories, fragrances, make-up and skin care products, smartphones and accessories, software, and tablets and accessories ${ }^{5}$. Our data include 1,685 ad instances for the five retailers that aired on 83 television programs. To control for online advertising spending, we also collect data on internet display spend, internet search spend, and online video spend by the retailers from Stradegy ${ }^{6}$.

\subsection{Social Media Data}

We supplement these data with minute-level Twitter mentions about the television programs in which the ads air and about the retailers. Program-related Twitter mentions were collected via Topsy Pro, and retailer-related Twitter mentions were collected via Crimson Hexagon. At the time of collection, both Topsy Pro and Crimson Hexagon were certified Twitter partners with access to the public firehose of Twitter posts ${ }^{7}$. We focus on Twitter mentions because the

\footnotetext{
${ }^{3}$ Table A1 in the Online Appendix provides demographic information on the comScore panel for users that visited at least one of the retailer's websites during this time period.

${ }^{4}$ This advertising data contains only live programming in the Eastern and Central Time Zones, which accounts for $76 \%$ of the U.S. population (based on U.S. Census Bureau 2013 State Population Estimates). Programming in the Pacific Time Zone is not deemed an initial broadcasting since it airs three hours after Eastern/Central programming. The comScore data is also filtered to exclude consumers in the Pacific Time Zone. The granular level of the social media data, discussed next, allows us to attribute the online WOM to the Eastern/Central Time Zone programming.

${ }^{5}$ While having data for five retailers may limit the importance and generalizability of our results, the large economic importance of these retailers and diverse range of products they advertise help alleviate these concerns.

${ }^{6}$ The correlations between monthly network television spending and these three measures of online advertising spending are as follows: network television and internet display spending 0.48 , network television and internet search spending 0.00 , and network television and online video spending 0.52 .

${ }^{7}$ Topsy Pro was acquired by Apple after our collection of program-related Twitter mentions but prior to the collection of retailer-related mentions. Since public access to Topsy Pro was no longer available following the acquisition, we acquired data on retailer-related Twitter mentions through Crimson Hexagon. These platforms offered comparable access to public
} 
majority of public social media chatter about television occur on Twitter (Schreiner 2013).

Twitter mentions for programs and retailers were gathered by tallying Tweets that contain the program/retailer's name, a hashtag(s) with a program/retailer's name, or the Twitter handle of the program/retailer. For program mentions, we expand this search criteria to include nicknames (e.g., DWTS for Dancing with the Stars) to capture as much chatter as possible about the programs. We use the program mentions to measure online program engagement and retailer mentions to control for its impact. For the latter, while past studies have found evidence of a positive relationship between online brand WOM and sales (e.g., Babić Rosario et al. 2016; You et al. 2015), engaging in online WOM about ads may distract viewers from conversing online about the show or from online shopping. Thus, we account for retailer chatter in our analysis.

\subsection{Advertisement and Program Characteristics}

We supplement our data with ad and program characteristics to control for their impacts on online shopping and to provide insights into our second research question - how can television advertising increase online shopping activity? We account for ad position as past work on television advertising has found that ad response varies with ad position (e.g., Danaher and Green 1997; Schweidel et al. 2014). Specifically, we control for when the ad airs (time, day, and month), position of the ad in the commercial break and in the program, whether the ad airs near a half-hour interval or not, and whether the ad runs concurrently with another ad break on a different broadcast network or not. The data on ad position were extracted from Stradegy.

We also account for measures of ad content that can influence ad effectiveness (e.g., Fossen and Schweidel 2017; Liaukonyte et al. 2015; Stewart and Furse 1986), including ad

Twitter posts. The only difference is that Crimson Hexagon's minute-level volume numbers are truncated if a given search query tallies more than 10,000 posts a day. If this occurs, Crimson Hexagon reports a random sample of 10,000 posts from that day. Given this random sample, the fraction of Tweets out of 10,000 occurring in a given time period before and after an ad should not be affected. Thus, a measure of change in Tweets about the retailer around an ad should not be impacted by this truncation. Given this, we use a relative change measure of online retailer mentions in our model (see Table 5). 
length, website calls-to-action, and references to a price. Ad length is provided by Stradegy. Each ad in the data was viewed by two coders to identify if the ad contains a web address and refers to price ${ }^{8}$. Given that ad effectiveness in social shows may vary with ad mood, as discussed previously, we use ispot.tv, a television ad analytics firm, to identify the mood of the advertisements. They label ads as active, emotional, funny, informational, or sexy using a layered process of "automation, in-house editorial and crowd sourcing on our public website." The mood categories are mutually exclusive, with each ad assigned to one category. iSpot.tv allows "active" to describe ads that do not fall into one of the four other mood categories.

We include program-specific effects to control for the impact of the program and its characteristics on ad response. We also control for if an ad airs during a season premiere or fall finale episode as viewers' responses to ads may vary during such episodes (Fossen and Schweidel 2017). Lastly, to control for the number of viewers exposed to ad $i$, we collect data on audience size from comScore, Inc.'s TV Essentials database, which includes viewing data collected from more than 20 million U.S. households. We use the U.S. audience size estimate for the 30-second interval (the granularity provided by TV Essentials) in which ad $i$ begins airing.

\subsection{Descriptive Statistics}

Tables 1-4 show descriptive statistics for the online shopping, advertising, and social media data across the retailers. The retailers vary in advertising between one and 19 products and airing between four and 771 ad instances during the fall 2013 television season (Table 1). Four out of the five retailers vary the mood of their ads across this time period. The majority of ad instances in the data have an active mood (72\%) followed by an informational mood (14\%), funny mood $(11 \%)$, sexy mood (2\%), and emotional mood $(1 \%)$. The retailers on average utilize just under

\footnotetext{
${ }^{8}$ Coders followed Stewart and Furse (1986) to define if ads referred to price. Initial agreement was $99 \%$ on if the ad contained a web address and $100 \%$ on if the ad referred to price, with differences reconciled through discussion of the ad.
} 
three ad mood types in their broadcast ad campaigns during the fall 2013 season. Each ad mood is employed by at least two retailers and is featured in at least eleven ad instances and three ad creatives. Additionally, each of the ad mood types is employed across the two retailers where the majority of purchases occurs. We leverage this variation within retailers in terms of ad mood strategies and unique ad creatives and ad instances aired to explore the relationship between social TV activity and ad response in terms of viewers' post-ad online shopping behavior'.

[Insert Tables 1 and 2 Here]

Tables 2 and 3 show how online chatter about the retailers and programs changes around the ads. Retailer chatter increases by an average of $8 \%$ in the five-minute window post-ad compared to the five-minute window pre-ad, but these increases vary across retailers and have large standard deviations. Figure $1^{10}$ provides further evidence that retailer chatter appears to increase post-ad for most retailers, but this effect subsides quickly, consistent with work on advertising and WOM (Fossen and Schweidel 2017). In Table 3, we see variation in the volume of program mentions around the ads. The ads air in programs that average 281 program mentions per minute up until the ads' airings, and program chatter in the minute before an ad airs is higher than its per minute average in the episode leading up until the ad's airing. Both of these metrics of online program engagement have large standard deviations. Table A4 in the Online Appendix presents descriptive statistics for online program chatter across the 83 programs in the data and illustrates the substantial variation in program WOM leading up to the ads and in the minute before ads air, both across the episodes of a given program and across programs. This suggests

\footnotetext{
${ }^{9}$ For robustness, we test two alternative models where we combine the ad mood types with less variation in terms of the number of ad instances and creatives. Specifically, we combine (1) emotional and sexy ads and (2) funny, emotional, and sexy ads. The results from these models are statistically consistent with the main model (see Online Appendix). ${ }^{10}$ Note that Table 2 and Figure 1 present different visualizations of the online retailer chatter data: percentage change in online retailer mentions from the five-minute window post-ad compared to the five-minute window pre-ad (Table 2) and volume of retailer mentions summed across all ad instances for a given retailer (Figure 1). We present similar visualizations of the web traffic (online purchases) data in Table 4 and Figure 1 (Table 4 and Figure 3).
} 
that the variation in program chatter is not solely determined by fixed program or audience characteristics (e.g., program features, genre, network, time aired, viewer demographics) ${ }^{11}$.

[Insert Table 3 and Figure 1 Here]

Per our data agreement, we cannot present volume of web traffic or sales at the retailerlevel, as this could provide identifying information about the retailers. We can illustrate the volume of the online shopping activity summed across retailers and present non-volume descriptive statistics at the retailer-level. In total, 28,763 unique comScore panelists generated 438,663 web sessions to the retailers' websites from Sept. 1-Dec 31, 2013. 6,462 of these web sessions occur within five minutes of an advertisement. Additionally, 9,836 unique panelists generated 23,003 transactions for a total of 25,040 products purchased at the retailers' websites from Sept. 1-Dec 31, $2013^{12}$. The average total basket price per transaction is $\$ 90.377$ of these transactions are generated by web sessions initiated within five minutes of an $\mathrm{ad}^{13}$. In Figure 2 , we illustrate the volume of web sessions and transactions at the retailers' websites summed across the five retailers as well as the volume of national, primetime, broadcast ads aired by the retailers across the fall 2013 television season. Not surprisingly, the volume of web sessions and transactions have similar patterns, peaking in the holiday shopping season.

[Insert Figure 2 Here]

Table 4 and Figures 1, 3, and 4 show traffic and sales on the retailers' websites around the ads. The vast majority of ad instances in our data see web traffic activity in the five-minute window post-ad (Table 4). The retailers see an average increase in traffic of $20 \%$ in the fiveminute post-ad window compared to the five-minute pre-ad window, but the standard deviations

\footnotetext{
${ }^{11}$ Additional descriptive statistics for online program chatter are shown in Figure A1 in the Online Appendix, which displays the time-series of average program mentions per minute around the ads' airings across ad position.

${ }^{12}$ We consider both the number of transactions and products purchased (henceforth purchases) in our analysis.

${ }^{13}$ Once a web session has been initiated, we allow 24 hours for the users to make a purchase, acknowledging that purchase decisions take time to occur once a website visit is initiated (Liaukonyte et al. 2015)
} 
are large. From Figure 1 we see that while some retailers see increases in traffic post-ad, the impact for other retailers is less clear. This appear consistent with Liaukonyte et al. (2015), who find that three out of seven retailers do not have significant product effects on web traffic post-ad while three (one) have mainly positive (negative) impacts on traffic post-ad. Figure 4 presents the relationship between changes in web traffic around ads and social TV, and it shows, across all ad instances, (1) a positive relationship between the change in traffic and the volume of program chatter leading up to an ad and (2) a positive relationship between the change in traffic and the change in program chatter in the minute prior to an ad's airing. We also see that the changes in web traffic may vary across levels of the social TV measures and across ad mood. Figure 4 may also suggest possible non-linear relationships between online program engagement and web traffic.

\section{[Insert Table 4 and Figures 3 and 4 Here]}

For online sales, the average conversion rate across retailers is 6\% (Table 4), which is similar to the $7 \%$ conversion rate for retailers found by Liaukonyte et al. (2015) in their work on online shopping $^{14}$. In Figure 3, we see evidence that more sales are generated in the short-term period post-ad than in the corresponding period pre-ad. Similarly, Table 4 reveals that retailers see an increase in sales when comparing purchases post-ad to purchases pre-ad, but these estimates have large standard deviations. Figure 4 presents the relationship between social TV and changes in purchases around ads. Across all ad instances, Figure 4 shows a slight negative linear relationship between the change in purchases and the volume of program chatter leading

\footnotetext{
${ }^{14}$ Conversion rate is calculated as: (number of sessions initiated within 5 minutes of an ad that generate a transaction in the next 24 hours)/(number of sessions initiated within 5 minutes of an ad). Liaukonyte et al. (2015) calculate conversion rates across the entire time window of their data. While two retailers in our data have high conversion rates (19\% and 25\%), they are similar to Liaukonyte et al. (2015) who find a 15\% conversion rate for one retailer and conversion rates exceeding $20 \%$ for three other websites. As we consider traffic initiated immediately following an ad, we may see higher conversion rates as those consumers that go to a brand's website post-ad may have higher purchase intentions.
} 
up to an ad but may illustrate a non-linear relationship where purchases increase as program chatter increases, with diminishing returns at higher levels of chatter. Figure 4 also shows a slight positive relationship between the change in purchases and the change in program chatter in the minute prior to an ad's airing. As with traffic, we also see evidence in Figure 4 that the changes in online purchases may vary across levels of online program engagement and across ad mood as well as evidence of possible non-linear relationships between online program engagement and online purchases.

Overall, Figure 4 suggests that online program engagement may have a meaningful relationship with ad response in terms of subsequent online shopping. However, these descriptive statistics do not model non-linear impacts of program engagement or control for other factors that may impact ad response. Thus, a formal model is needed to explore the relationship between online program engagement and online shopping, which we describe in the next section.

As shown in Table 4, most purchase activity is generated at two of the five retailers. While most ad instances have web traffic activity in the five-minute post-ad window, few ad instances generate transactions from the web traffic in the five-minute window post-ad. To overcome this limitation and ensure that there is sufficient variation to estimate how social TV relates to web traffic and sales, we estimate our model on 60 variants of the data (main model and 59 alternative analyses). These analyses include considering traffic and purchases from one to 60 minutes post-ad, varying the purchase consideration window, considering only ad creatives with sales activity (ad creatives that have at least one web session initiated within five minutes of the ad generate a purchase in the next 24 hours), considering only ad instances with sales activity (ad instances with at least one web session initiated within five minutes of the ad that generate a purchase in the next 24 hours), varying the operationalization of the outcome measures, and 
varying the ad mood categories. All 60 analyses present, at a minimum, directionally consistent results and are discussed in the following sections and detailed in the Online Appendix.

\section{Model}

To assess the relationship among television advertising, social TV, and online shopping, we model both online traffic and purchases ${ }^{15}$ following the airing of advertisement $i$ as follows:

$$
\begin{gathered}
\left(\begin{array}{c}
\text { LogSessionsPostAd } \\
\text { LogPurchasesPostAd }
\end{array}\right) \sim N\left(\begin{array}{l}
\hat{Y}_{i 1}, T \\
\hat{Y}_{i 2}, T
\end{array}\right) \\
\hat{Y}_{i 1}=\mu_{\text {ses }}+\alpha_{r[i], 1}+\gamma_{p[i], 1}+\beta_{1,1} \cdot \text { LogSessionsPreAd }_{i}+\beta_{2,1} \\
\text { LogPurchasesPreAd }_{i}+\sum_{k=1}^{59} \theta_{k 1} \cdot X_{i k} \\
\hat{Y}_{i 2}=\mu_{\text {pur }}+\alpha_{r[i], 2}+\gamma_{p[i], 2}+\beta_{1,2} \cdot \text { LogSessionsPreAd }_{i}+\beta_{2,2} \\
\text { LogPurchasesPreAd }_{i}+\beta_{3} \cdot \operatorname{LogSessionsPostAd}{ }_{i}+\sum_{k=1}^{59} \theta_{k 2} \cdot X_{i k}
\end{gathered}
$$

where $\mu_{\text {ses }}$ and $\mu_{\text {pur }}$ are intercepts. $\alpha_{r}$. are retailer-specific effects for the five retailers ${ }^{16}$, and $\gamma_{p}$. are program-specific effects for the 83 programs. These effects account for unobservable differences across retailers and programs that may impact our outcomes (e.g., program attractiveness to advertisers or demographics $)^{17}$. In our main analysis, LogSessionsPostAd ${ }_{i}\left(\right.$ LogSessionsPreAd $\left._{i}\right)$ is the log of the number of web sessions initiated at the website for the retailer in ad $i$ between when ad $i$ airs until five minutes after ad $i$ airs (between five minutes prior to ad $i$ until ad $i$ ). LogPurchasesPreAd $i$ is the log of the number of purchases on the retailer's website between five

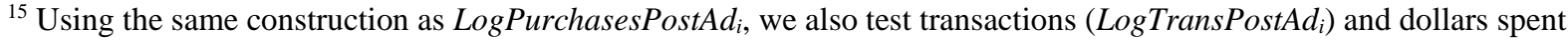
$\left(\right.$ LogSpendPostAd $\left._{i}\right)$. The correlation between LogTransPostAd LogSpendPostAd $\left._{i}\right)$ and LogPurchasesPostAd Lis $_{i}$.997 (0.940). The results from these two alternative specifications do not differ from those of the main model.

${ }^{16}$ For robustness, we also test two sets of time-varying retailer-specific effects that vary by month and by week, respectively. The results from these two alternative specifications do not differ from those of the main model.

${ }^{17}$ We also test variables for program genre and network. These controls were not significant, and model fit in terms of both MAE and DIC was inferior to the proposed model. Thus, these controls were excluded from $X_{i k}$.
} 
minutes prior to ad $i$ airs until ad $i$ airs. LogPurchasesPostAd $i$ is the log of the number of purchases generated by sessions initiated on the retailer's website between when ad $i$ airs until five minutes after ad $i$. We consider the volume of purchases that occur within 24 hours by these sessions that were initiated in the five-minute period post-ad. Thus, if a user initiated a session in the five-minute window post ad $i$ on the website of the retailer in ad $i$, we track her purchasing behavior over the next 24 hours to see if she made a purchase on the retailer's website. The oneday purchase consideration window for LogPurchasesPostAd $d_{i}$ acknowledges that purchase decisions take time to occur once a website visit is initiated (Liaukonyte et al. 2015) ${ }^{18}$.

Lastly, $X_{i}$. is a vector of ad and program characteristics, which are summarized in Table 5. We assess the relationship between social TV activity about the program and online shopping by considering both the volume of online program mentions up until ad $i$ airs (LogPWOMVolume $\left.{ }_{i}\right)$

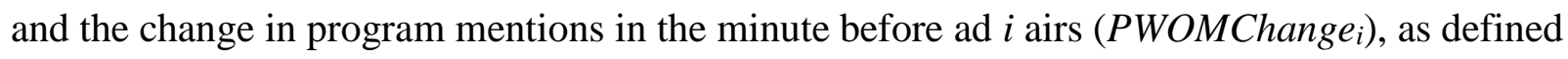
in Table 5. We include quadratic terms for both measures to allow their effects to be non-linear (e.g., Tavassoli et al. 1995). $X_{i}$. also includes the variables discussed in the data section, including ad mood, retailer chatter, online ad spending by the retailers, and interactions among the two measures of online program engagement and the ad mood variables. Given these interactions, the coefficients for online program engagement capture the relationship between online program engagement and online shopping for the baseline ad mood category (funny ads). The correlations among the variables in equations (2)-(3) are shown in Online Appendix Table A5. Of note, LogPWOMVolume $_{i}$ and PWOMChange $e_{i}$ are not highly correlated (0.06).

\footnotetext{
${ }^{18}$ We take the log plus one to avoid taking the log of zero. We test several alternative specifications, including varying the time from the ad from one minute to one hour and varying the purchase consideration window for LogPurchasesPostAd from 15 minutes to 72 hours. We also estimate the model without the log transformation on the outcomes and online shopping measures. Finally, we test three alternative specifications of the outcome measures: difference (e.g., $\log \left(\left(\right.\right.$ SessionsPostAd $_{i}-$ SessionsPreAd $\left.\left.\left._{i}\right)+1\right)\right)$, percentage change (e.g., $\log \left(\left(\right.\right.$ SessionsPostAd $_{i}-$

SessionsPreAd $\left.\left.\left.d_{i}\right) /\left(\operatorname{Sessions}_{\operatorname{PreA}} d_{i}+1\right)\right)\right)$, and ratio (e.g., $\left.\log \left(\operatorname{SessionsPostAd}_{i} /\left(\operatorname{SessionsPreAd}_{i}+1\right)\right)\right)$. The key results from these analyses are, at a minimum, directionally consistent and are detailed in the Online Appendix.
} 
Following the identification strategy used in past research on the effects of television on online behaviors (Fossen and Schweidel 2017; Lewis and Reiley 2013; Liaukonyte et al. 2015), we employ narrow time windows around the ads to better attribute changes in online shopping activity to the focal variables of interest. As the television ad buying process restricts advertisers' control of when and where their ads will air (e.g., Katz 2013), the use of narrow time windows prevents bias in the results that could arise from advertisers choosing a certain time window to air an advertisement to impact online shopping (Liaukonyte et al. 2015). Advertisers buy the vast majority of ad time in the upfront markets, which occur months prior to the fall television season. At best, the ability to stipulate when a specific ad will air is restricted to the quarter-hour level; however, this timing is rarely stated in advertiser-network contracts, and even which program the ads will air on is not often stipulated (Liaukonyte et al. 2015). Networks further restrict any jurisdiction over when an ad will air by commonly ordering ads at random across commercial breaks and by employing "make-good" policies that allow ads that have not reached the number of viewers paid for by the advertisers to be re-run on different programs on different days (Katz 2013; Wilbur et al. 2013). This process not only impedes advertisers control over selecting a specific program to air an ad in, but it also alleviates the concern that advertisers could time an ad to air during a specific minute-level time window to influence web traffic and sales. Additionally, given this lack of control by advertisers of when and where their ads will air, it is unlikely that advertisers could push out additional promotional materials between when their ads air and five minutes after that could inflate the effect sizes in our model estimation ${ }^{19}$.

\footnotetext{
${ }^{19}$ This argument is strongest for shorter time windows around when the ad airs. Longer time windows capture more online activity but increase concerns about the degree to which advertisers may choose when an ad airs. To assess the robustness of our findings, we test alternative time windows around when the ad airs from one to sixty minutes. We also test three shorter purchase consideration windows $(15,30$, and 60 minutes). The results from all of these analyses are highly consistent with our main model (see Online Appendix).
} 
Equations (1)-(3) are estimated jointly using a Bayesian hierarchical regression and Markov chain Monte Carlo techniques in WinBUGS. We specify $\mu_{s e s}, \mu_{p u r}, \beta_{1 .}, \beta_{2 .}, \beta_{3}$, and $\theta_{k}$. with diffuse normal priors. We assume that $\alpha_{r, 1} \sim N\left(0, \tau_{\alpha 1}\right), \alpha_{r, 2} \sim N\left(0, \tau_{\alpha 2}\right), \gamma_{p, 1} \sim N\left(0, \tau_{\gamma 1}\right)$, and $\gamma_{p, 2} \sim$ $N\left(0, \tau_{\gamma_{2}}\right)$, with diffuse inverse-gamma priors for the variances. Lastly, we allow for contemporaneous covariance in $\mathrm{T}$ and assume it has a diffuse inverse Wishart prior. Equations (1)-(3) are estimated jointly from three independent chain runs of 200,000 iterations with the first 100,000 iterations discarded as a burn-in. We sample every fifth iteration, leaving our inferences based on 20,000 iterations from each chain. Model convergence was assessed using the time series plots of the posterior draws for each parameter.

\section{Results}

\subsection{Model Comparison}

We use deviance information criterion (DIC), a likelihood-based measure that penalizes complex models, and mean absolute error (MAE) to compare our proposed model to three alternatives. Lower DIC and MAE indicate better model fit. We first consider a baseline model (Model 1) that excludes social TV, retailer-specific effects $\left(\alpha_{r}\right)$, and program-specific effects $\left(\gamma_{p}\right)$. Model 2 builds on Model 1 by including $\alpha_{r}$. and $\gamma_{p}$. We then examine the impact of social TV activity without ad mood interactions (Model 3) and with these interactions (Model 4, our proposed model). The posterior mean estimates for DIC and MAE, which are shown in Online Appendix Table A6, indicate that accounting for retailer- and program-specific effects and social TV activity is important in exploring the relationship between television advertising and online shopping activity, as these variables improve model fit. Incorporating online program engagement interactions with ad mood further improves model fit (Model 4). As Model 4 is the best fitting model, we focus the results discussion on the findings from this model. 


\subsection{Impact of Online Retailer Chatter, Advertisement Characteristics, and Program}

\section{Characteristics on Online Traffic and Purchases}

Tables 6-8 and Online Appendix Tables A7 and A8 show our results for the effects of ad and program characteristics on online traffic and purchases. Of note, we find that increases in online retailer chatter relate to increases in traffic to the retailers' websites in the five-minute window post-ad; however, this effect diminishes at higher values of retailer chatter (Table 6). These results may suggest that ads that spur immediate increases in online brand chatter may also spur increases in web traffic to the brands' website. We also see some marginal evidence that ads mentioning price ${ }^{20}$ and increases in internet search advertising spending are associated with increases in online sales. Additionally, we do not find a significant impact of audience size on online shopping. This result may occur because audience size does not meaningfully impact online shopping beyond our other model controls, such as when the ad airs and program-specific effects. This result is consistent with recent research that has found no relationship between program ratings and media multitasking activities, such as online program chatter during the program (e.g., Fossen and Schweidel 2017; Seiler et al. 2017).

We also find that when an ad airs can impact subsequent online shopping (Table 7). Ads near a half-hour interval (e.g., 8:28pm, 9:02pm) spur more online purchases compared to ads in other time slots. Additionally, ads that air earlier in primetime (relative to ads that air between 10:45-10:59pm) generate more subsequent traffic. We estimate that ads airing earlier in primetime can spur as much as 381 more web visits than ads airing between 10:45-10:59 $\mathrm{pm}^{21}$. We also find that ads in October and November spur less traffic than ads in December, which

\footnotetext{
${ }^{20}$ If we exclude retailer-specific effects, mentioning price relates to significant increases in both online traffic and purchases, with the $95 \%$ credible intervals excluding zero.

${ }^{21}$ To illustrate the effect size of our results beyond comScore's panel of 100,000 active U.S. internet users, we extrapolate our findings from the panel to the 91,109,500 estimated households in the U.S. that had internet in 2013 (File and Ryan 2014; United States Census Bureau 2013) to assess what the effects might be for the U.S population.
} 
may be due to the holiday season. Additionally, ads airing on Monday, Tuesday, Wednesday, or Sunday (Saturday) generate more (less) immediate traffic than ads airing on Friday, and ads in fall finale episodes generate fewer immediate online purchases than ads on other episodes. These results may be driven by the characteristics of the show and/or by the characteristics of the media multitasking behavior of viewers during these periods.

\section{[Insert Tables 6 and 7 about Here]}

Lastly, for the main effects of ad mood (Table 8), we see that informational and active ads may encourage more immediate purchasing activity than funny ads. We will evaluate the ad mood interactions with social TV activity in the next section.

\subsection{Is Online Program Engagement Linked to Online Traffic and Purchases?}

We find that social TV activity about programs matters when assessing television advertising's impact on online shopping. In particular, we find significant interactions between online program engagement and ad mood, suggesting that online program engagement may moderate the effect of ad mood on online shopping behavior (Table 8). If we evaluate $\operatorname{LogPWOMVolume}_{i}$ and PWOMChange $e_{i}$ separately, we find that emotional ads are more effective than funny ads at increasing immediate web traffic when the volume of social TV activity is high. Additionally, we see that higher volumes of social TV activity relate to increases in online purchases for the baseline ad mood category, funny advertisements. Emotional and sexy ads do not significantly differ in their impacts on purchases from funny ads, which may be because these ad types are similarly successful as funny ads at increasing purchases when the volume of social TV activity is high but may also be because of the small sample size of ad instances categorized by these ad mood types. We also see in Table 8 that active and informational ads are less effective at encouraging immediate online purchases than funny ads when the volume of social TV activity 
is high. When we evaluate the impact of the change in online program chatter immediately prior to an ad's airing on online purchases, we see the opposite pattern (Table 8). To consider the impact of both social TV activity measures together, we show the combined impact of these measures on online shopping activity for different ad moods across different values of PWOMVolume $_{i}$ and PWOMChange $e_{i}$ in Tables 9 and 10 and Figure $5^{22}$. As these effects combine the main effects of online program engagement and their interactions with ad mood, we focus our discussion on these results to assess whether social shows are good for advertisers.

[Insert Table 8 about Here]

For traffic to the retailers' websites, only the posterior mean estimates for emotional ads significantly differ from funny ads, the baseline mood (Table 9). Specifically, we see evidence that emotional ads spur more traffic than funny ads when they air in shows with a high volume of online program chatter leading up to the ad (PWOMVolume $)$ and low change in program chatter in the minute before the ad (PWOMChange $\left.e_{i}\right)$. These results are consistent with the findings in Table 8. To illustrate the effect size, if an emotional ad aired in a program when PWOMChange ${ }_{i}$ $=0.5$ (program chatter in the minute before the ad is half of the average program chatter volume leading up to the ad) and below average volume of program chatter $\left(P\right.$ WOMVolume $i$ at $1^{\text {st }}$ quartile), this ad would spur an estimated 719 more web visits to the retailer's website in the five-minute period post-ad than funny ads. Holding PWOMChange $e_{i}$ constant, if the ad aired in a program with a higher volume of program chatter (PWOMVolume ${ }_{i}$ at median), this ad would generate 1,117 more web visits in the five-minute period post-ad than funny ads ${ }^{23}$.

[Insert Tables 9 and 10 about here]

\footnotetext{
${ }^{22}$ This combined effect sums the ad mood effect and linear and quadratic effect for both online program engagement measures. As an example, for active mood in the sales equation, it is calculated as $\theta_{3,2}+\theta_{7,2} *$ PWOMVolume $_{i}+$ $\theta_{8,2} *$ PWOMVolume ${ }_{i}^{2}+\theta_{9,2} *$ PWOMChange $_{i}+\theta_{10,2} *$ PWOMChange ${ }_{i}{ }^{2}$ for the different values of PWOMVolume $i$ and PWOMChange . $_{\text {. }}$

${ }^{23}$ See note under Table 6 about effect size calculations.
} 
For online sales, we find that funny ads generate substantial increases in purchases when they air in social shows (Table 10). This effect holds across both measures of online program engagement. We further find that emotional ads and, in most cases, sexy ads do not significantly differ from funny ads, which may be because these two ad types are as successful in social shows as funny ads in terms of increasing online purchases or because the small sample size of ad instances categorized by these ad mood types impacts significance. While informational and active ads spur larger increases in online purchases when they air in shows with higher levels of online program engagement ${ }^{24}$, they do not perform as well as funny ads. Figure 5 illustrates this pattern by showing the estimated effect size of the impact of online program engagement (at different levels of $P W O M$ Volume $_{i}$ and $\left.P W O M C h a n g e_{i}\right)$ on online purchases for funny, active, and informational ads.

In comparing the results when evaluating the impacts of social TV activity separately (Table 8) vs. together (Tables 9 and 10), the findings in Tables 9 and 10 are consistent with the impacts of the volume of social TV activity and the quadratic effect of the change in online program chatter in the minute before the ad airs shown in Table 8 . This may indicate that these factors play an important role in evaluating the relationship between social TV activity and online shopping activity.

In summary, we find evidence that social shows benefit advertisers in terms of driving online shopping at the advertisers' website post-ad, with emotional ads spurring the largest increases in web traffic and funny ads spurring the largest increases in online sales. We also find that ads with an active or informational mood are less effective than funny ads at increasing

\footnotetext{
${ }^{24}$ The magnitude of the positive posterior mean estimates of the baseline category funny ads is larger than the magnitude of the negative posterior mean estimates for informational and active ads. For informational ads (active ads), these effects

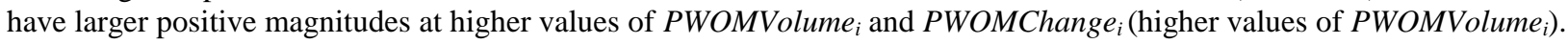


online sales post-ad when they air in more social shows. These results may be consistent with work that has found affective ads to be more successful in capturing viewers' attention, especially relative to rational ads (e.g., Eisend 2009; Olney et al. 1991; Sternthal and Craig 1973; Zillmann et al. 1980), which may allow for the engaged processing with the program to spillover to ad processing. This argument is in line with increased show involvement enhancing viewers' opportunities to process ads while concurrently reducing motivation or ability to process ads (e.g., MacInnis et al. 1991). Our results may suggest that advertisements that increase viewer attention can circumvent these potential negative impacts of increased program involvement.

\subsection{Robustness Checks}

To analyze the robustness of the results, we estimate 59 additional models. These include considering online shopping activity from one to 60 minutes post-ad and varying the purchase window of LogPurchasesPostAd from 15 minutes to 72 hours. We also estimate the model on (1) only ad creatives in which at least one web sessions initiated within five minutes of the ad generates a purchase in the next 24 hours and (2) only ad instances in which at least one web session initiated within five minutes of the ad generates a purchase in the next 24 hours. We also estimate the model without the use of log transformation and test three alternative outcome measures (difference, percentage change, and ratio measures). Lastly, we estimate two models where we combine the ad moods with less variation in terms of the number of ad instances and ad creatives. The results from all 59 of these analyses are, at a minimum, directionally consistent with our main results. These analyses are detailed in the Online Appendix.

\section{Discussion}


We explore the relationship among television advertising, social TV, and online shopping for five large retailers and find that social shows are beneficial for advertisers with the extent of this benefit depending on the mood of the advertisement. Our results suggest that ads with a funny or emotional mood are most effective at spurring immediate online shopping activity when they air in more social shows. While informational and active ads also increase online shopping activity, they are less effective than ads with other moods when they air in more social shows. We also find that a number of ad design and media planning strategies can influence online shopping following ads. We discuss the implications of our results for retailers and television networks.

\subsection{Implications for Retailers}

Our results contribute to the debate that media multitasking by television viewers is not bad news for advertisers (Fossen and Schweidel 2017; Liaukonyte et al. 2015). The primary implication from our results for retailers is that advertising in social shows may be a good strategy for increasing immediate online shopping activity, validating industry reports that social shows offer more engaged audiences (e.g., Nielsen 2015a; Nielsen 2015b). Retailers interested in leveraging the full benefits of social shows should air more affective advertisements, rather than more rational or informational ads, in social shows. These findings highlight the importance of ad mood in improving ad effectiveness in the age of media multitasking television viewers.

Our investigation provides further insights for retailers on how to improve ad design strategies to increase online shopping activity post-ad. Retailers should consider implementing ad design strategies that increase immediate online chatter (Fossen and Schweidel 2017), as ads that increase retailer chatter also result in subsequent increases in web traffic to the retailers' websites. Retailers should also consider referring to price in their advertisements and airing ads earlier in primetime, near half-hour breaks, between Sunday and Wednesday, and on non-fall 
finale episodes to increase online shopping activity post-ad. The last effect is interesting, as ad time in fall finale episodes is often considered attractive to advertisers. It may be the case, however, that viewers of such episodes have difficulty re-directing their attention from the program to the ads. Such exploration may be a productive avenue for future research.

\subsection{Implications for Television Networks}

The television industry has faced challenges in incorporating program engagement into ad buys, due to ambiguity over its definition and its value to advertisers (e.g., Calder et al. 2009). Our findings suggest that shows with more program-related social media activity add value to advertisers by contributing to incremental web traffic and sales. These results highlight the importance of television networks having a social strategy for their shows that encourages viewers to engage in social TV. Television networks can also utilize these results to provide support as to why program engagement should be incorporated into the media buying process and to advocate for higher ad rates in their social shows. A fruitful avenue of future research may be to explore how the content of shows can increase social TV activity about the program.

\subsection{Limitations and Directions for Future Research}

Our investigation is subject to limitations that we hope may encourage future work on media context and cross-media effects. First, our data do not allow for the direct observation of an individual viewer's online behavior nor exposure to advertising and social media. Such data would allow for examinations of within-viewer variation in social TV activity, the impact of viewer characteristics on cross-media effects, and longer time windows around ads that may capture longer-term ad effects. Given the aggregate nature of our data, as in prior research on television advertising's impact on online behaviors (e.g., Fossen and Schweidel 2017;

Liaukonyte et al. 2015), we exploit narrow time windows around ads to attribute changes in 
online program engagement to changes in online shopping activity. While our robustness checks provide some assurance that we have limited the potential impact of confounding factors such as other marketing efforts that may coincide with television advertising, our research is subject to the limitations and challenges with measuring television advertising effectiveness, as detailed by Lewis and Reiley (2013). While a large-scale, individual-level randomized experiment would be ideal, such experiments are not currently possible given the state of television technology (Lewis and Rao 2015; Lewis and Reiley 2013). Recent work has argued that changes in behavior in narrow time windows around a television advertisement as measured through aggregate-level, secondary data is a sound approach to measuring television advertising effectiveness that can produce results similar to a randomized experiment (e.g., Fossen and Schweidel 2017; Joo et al. 2014; Lewis and Reiley 2013; Liaukonyte et al. 2015). However, the benefits of narrow time windows for identification come with the limitation of underestimating the effect size of ad effectiveness due to excluding the possibility of longer-term impacts (Lewis and Reiley 2013).

Second, our aim is to explore whether or not social shows benefit advertisers, and we use measures of online program engagement to do so. As our data discussion reveals, these measures of online engagement have rich variation across episodes of a show and across shows, suggesting that program chatter during the show is not solely determined by fixed program or audience characteristics (e.g., program features, genre, network, viewer demographics). Measures of social TV activity may serve as an observable proxy for overall viewer engagement as online program engagement may correlate with offline measures of viewer engagement such as increased attention or arousal (Nielsen 2015a). Future research may probe the extent to which offline measures of viewer engagement are also related to online (and offline) shopping behavior. 
Third, our analysis is limited to five large retailers. Table A1 in the Online Appendix suggests that the consumers that shopped at the retailers in our dataset may deviate from the U.S. population in terms of probability to have children, education, and racial diversity. While we demonstrate that social shows can benefit retailers in terms of online shopping, future research may consider if this extends to other advertisers and to offline shopping. Fourth, future work may benefit from having a larger data set with more variation in key ad characteristics to further investigate moderators of social TV's impact on online shopping. Lastly, while some of our key results are consistent with past research, lab or field experiments may allow researchers to tease out the underlying behavioral mechanism driving the results in our empirical analysis. 


\section{References}

Babić Rosario A., F. Sotgiu, K. D. Valck, and T. H.A. Bijmolt (2016), "The Effect of Electronic Word of Mouth on Sales: A Meta-Analytic Review of Platform, Product, and Metric Factors,” Journal of Marketing Research, 53(June), 297-318.

Benton, A. and S. Hill (2012), "The Spoiler Effect? Designing Social TV Content that Promotes Ongoing WOM," Conference on Information Systems and Technology (CIST). Phoenix, AZ.

Brasel, A. S. and J. Gips (2011), "Media Multitasking Behavior: Concurrent Television and Computer Usage," Cyberpsychology, Behavior, and Social Networking, 14 (9), 527-34.

Calder, B. J., E. C. Malthouse, and U. Schaedel (2009), “An Experimental Study of the Relationship between Online Engagement and Advertising Effectiveness," Journal of Interactive Marketing, 23, 321-331.

Celsi, R. L. and J. C. Olson (1988), "The Role of Involvement in Attention and Comprehension Processes," Journal of Consumer Research, 15 (Sept), 210-224.

Dahlén, M. (2005), "The Medium as a Contextual Cue: Effects of Creative Media Choice," Journal of Advertising, 34 (3), 89-98.

Danaher, P. J. and B. J. Green (1997), "A Comparison of Media Factors that Influence the Effectiveness of Direct Response Television Advertising," Journal of Direct Marketing, 11(2), 46-58.

Eisend, M. (2009), "A Meta-Analysis of Humor in Advertising," Journal of the Academy of Marketing Science, 37, 191-203.

Feltham, T. S. and S. J. Arnold (1994), "Program Involvement and Ad/Program Consistency as Moderators of Program Context Effects," Journal of Consumer Psychology, 3(1), 51-77.

File, T. and C. Ryan (2014), "Computer and Internet Use in the United States: 2013," American Community Survey Reports, United States Census Bureau, (November), http://www.census.gov/content/dam/Census/library/publications/2014/acs/acs28.pdf.

Flomenbaum, A. (2016), "Exclusive: Nielsen Study Shows that TV Advertising Drives Earned Media for Brands on Twitter," The Drum, (February 21), http://www.thedrum.com/news/2016/02/21/exclusive-nielsen-study-shows-tv-advertising-drivesearned-media-brands-twitter.

Fossen, B. L. and D. A. Schweidel (2017), "Television Advertising and Online Word-of-Mouth: An Empirical Investigation of Social TV Activity," Marketing Science, 36(1), 105-123.

Gelper, S., R. Peres, and J. Eliashberg (2018), "Talk Bursts: The Role of Spikes in Pre-release Word-of-Mouth Dynamics," Journal of Marketing Research, forthcoming.

Godes D. and D. Mayzlin (2004), "Using Online Conversations to Study Word-of-Mouth Communication," Marketing Science, 23(4), 545-560.

Hinz, O., S. Hill, and J. Y. Kim (2016), “TV'S Dirty Little Secret: The Negative Effect of Popular TV on Online Auction Sales," MIS Quarterly, 40(3), 623-644.

IAB (2015), "The Changing TV Experience: Attitudes and Usage Across Multiple Screens," (April), http://www.iab.com/insights/the-changing-tv-experience-attitudes-and-usage-across-multiple-screens/.

Jeong, S. and Y. Hwang (2012), "Does Multitasking Increase or Decrease Persuasion? Effects of Multitasking on Comprehension and Counterarguing," Journal of Communication, 62(4), 571-87.

Johnson, E. J., W. W. Moe, P. S. Fader, S. Bellman, and G. L. Lohse (2004), “On the Depth and Dynamics of Online Search Behavior," Marketing Science, 50(3), 299-308.

Joo, M., K. C. Wilbur, B. Cowgill, and Y. Zhu (2014), “Television Advertising and Online Search,” Management Science, 60(1), 56-73.

Katz, H. (2013), The Media Handbook: A Complete Guide to Advertising Media Selection, Planning, Research, and Buying. New York: Routledge.

Kazakova, S., V. Cauberghe, L. Hudders, and C. Labyt (2016), “The Impact of Media Multitasking on the Cognitive and Attitudinal Responses to Television Commercials: The Moderating Role of Type of Advertising Appeal," Journal of Advertising, 45(4), 403-416.

Kilger, M. and E. Romer (2007), "Do Measures of Media Engagement Correlate with Product Purchase Likelihood?," Journal of Advertising Research, 47(3), 313-325.

Lewis, R.A. and J. M. Rao (2015), "The Unfavorable Economics of Measuring the Returns to Advertising," The Quarterly Journal of Economics, 130(4), 1941-1973

Lewis, R.A. and R.H. Reiley (2013), "Down-to-the-Minute Effects of Super Bowl Advertising on Online Search Behavior," 14th ACM Conference on Electronic Commerce, 9(4), Article 61 (June 2013).

Liaukonyte, J., T. Teixeira, and K. C. Wilbur (2015), “Television Advertising and Online Shopping,” Marketing Science, 34(3), 311-330.

Lord, K. R. and R. E. Burnkrant (1993), “Attention Versus Distraction: The Interactive Effect of Program Involvement and Attentional Devices on Commercial Processing," Journal of Advertising, 22(1), 47-60.

Lynch, J. (2015), "Why Some Low-Rated TV Shows Keep Getting Renewed," Adweek, (May 11), http://www.adweek.com/news/television/why-some-low-rated-tv-shows-keep-getting-renewed-164648.

MacInnis, D. J., A. G. Rao, and A. M. Weiss (2002), “Assessing When Increased Media Weight of Real-World Advertisements Helps Sales," Journal of Marketing Research, 39(4), 391-407.

MacInnis, D. J., C. Moorman, and B. J. Jaworski (1991), "Enhancing and Measuring Consumers' Motivation, Opportunity, and Ability to Process Brand Information from Ads," Journal of Marketing, 55(October), 32-53.

Montgomery, A., S. Li, K. Srinivasan, and J. C. Liechty (2004), "Modeling Online Browsing and Path Analysis Using Clickstream Data," Marketing Science, 23(4), 579-595. 
Murry, J.P., Jr., J.L. Lastovicka, and S. N. Singh (1992), "Feeling and Liking Responses to Television Programs: An Examination of Two Explanations for Media-Context Effects," Journal of Consumer Research, 18(4), 441-451.

Nielsen (2014), "What's Empowering the New Digital Consumer?," (February 10), http://www.nielsen.com/content/corporate/us/en/insights/news/2014/whats-empowering-the-new-digital-consumer.html.

Nielsen (2015a), "Social TV: A Bellwether for TV Audience Engagement," (March 9), http://www.nielsen.com/us/en/insights/news/2015/social-tv-a-bellwether-for-tv-audience-engagement.html.

Nielsen (2015b), "Live TV + Social Media = Engaged Viewers," (April 6), http://www.nielsen.com/us/en/insights/news/2015/live-tv-social-media-engaged-viewers.html.

Norris C. E. and A. M. Colman (1993), "Context Effects on Memory for Television Advertisements," Social Behavior and Personality, 21(4), 279-296.

Olney, T.J., M. B. Holbrook, and R. Batra (1991), "Consumer Responses to Advertising: The Effects of Ad Content, Emotions, and Attitude toward the Ad on Viewing Time," Journal of Consumer Research, 17(4), 440-453.

Pavelchak, M. A., J. H. Antil, and J. M. Munch (1988), "The Super Bowl: An Investigation into the Relationship Among Program Context, Emotional Experience, and Ad Recall," Journal of Consumer Research, 15(3), 360-67.

Russell, M. (2012), "Social TV Keeps Viewers Engaged When Minds Might Wander, Study Says,” AdAge, (July 3), http://adage.com/article/media/social-tv-viewers-engaged/235739/.

Schweidel, D. A., N. Z. Foutz, and R. J. Tanner (2014), "Synergy or Interference: The Effect of Product Placement on Commercial Break Audience Decline," Marketing Science, 33(6), 763-780.

Schweidel, D. A. and W. W. Moe (2016), "Binge Watching and Advertising," Journal of Marketing, 80(5), 1-19.

Schreiner, T. (2013), "Amplifiers Study: The Twitter Users Who Are Most Likely to Retweet and How to Engage Them," Twitter, (January 10), https://blog.twitter.com/2013/amplifiers-study-the-twitter-users-who-are-most-likely-to-retweet-andhow-to-engage-them.

Seiler, S., S. Yao, and W. Wang (2017), "Does Online Word-of-Mouth Increase Demand? (and How?) Evidence from a Natural Experiment," Marketing Science, 36(6), 838-861.

Singh, S.N. and J.C. Hitchon (1989), "The Intensifying Effects of Exciting Television Programs on the Reception of Subsequent Commercials," Psychology \& Marketing, 6(1), 1-31.

Sternthal, B. and C. S. Craig (1973), "Humor in Advertising," Journal of Marketing, 37(4), 12-18.

Stewart, D. W. and D. H. Furse (1986), Effective Television Advertising: A Study of 1000 Commercials. Lexington, MA: Lexington Books.

Tavassoli, N. T., C.J. Shultz, II, and G.J. Fitzsimons (1995), "Program Involvement: Are Moderate Levels Best for Ad Memory and Attitude Toward the Ad?," Journal of Advertising Research, 35(5), 61-72.

Teixeira, T. S, M. Wedel, and R. Pieters (2010), "Moment-to-Moment Optimal Branding in TV Commercials: Preventing Avoidance by Pulsing," Marketing Science, 29(5), 783-804.

Teixeira, T.S, R. Picard, and R. el Kaliouby (2014), "Why, When, and How Much to Entertain Consumers in Advertisements? A Web-Based Facial Tracking Field Study,” Marketing Science, 33(6), 809-827.

United States Census Bureau (2013), “America's Families and Living Arrangements: 2013: Households," http://www.census.gov/hhes/families/data/cps2013H.html.

Wang, J. and B. J. Calder (2009), "Media Engagement and Advertising: Transportation, Matching, Transference, and Intrusion," Journal of Consumer Psychology, 19(3), 546-555.

Wilbur, K. C., L. Xu, and D. Kempe (2013), “Correcting Audience Externalities in Television Advertising,” Marketing Science, 32(6), 892-912.

Woltman Elpers, J. L.C.M., M. Wedel, and R. G.M. Pieters (2003), "Why Do Consumers Stop Viewing Television Commercials? Two Experiments on the Influence of Moment-to-Moment Entertainment and Information Value," Journal of Marketing Research, 40(Nov), 437-453.

Xiong, G. and S. Bharadwaj (2014), "Prerelease Buzz Evolution Patterns and New Product Performance," Marketing Science, 33(3), 401-421.

Yoo, C. and D. MacInnis (2005), "The Brand Attitude Formation Process of Emotional and Informational Ads," Journal of Business Research, 58, 1397-1406.

You, Y., G. G. Vadakkepatt, and A. M. Joshi (2015), “A Meta-Analysis of Electronic Word-of-Mouth Elasticity,” Journal of Marketing, 79(March), 19-39.

Zhang, Y., M. Trusov, A. T. Stephen, and Z. Jamal (2017), “Online Shopping and Social Media: Friends or Foes?,” Journal of Marketing, 81(6), 24-41.

Zillmann, D., B. R Williams, J. Bryant, K. R. Boynton, and M. A. Wolf (1980), “Acquisition of Information from Educational Television as a Function of Differently Paced Humorous Inserts,” Journal of Educational Psychology, 72(2), 170-180. 
Table 1: Descriptive Statistics for Retailers' Advertisements, Ad Characteristics, and Program Characteristics

\begin{tabular}{|c|c|c|c|c|c|c|c|c|c|c|c|c|c|c|c|c|c|c|}
\hline \multirow{2}{*}{ Retailer } & \multirow{2}{*}{$\begin{array}{c}\text { Advertised } \\
\text { Products }\end{array}$} & \multirow{2}{*}{\multicolumn{2}{|c|}{$\begin{array}{c}\text { Unique Ad } \\
\text { Creatives }\end{array}$}} & \multirow{2}{*}{\multicolumn{2}{|c|}{$\begin{array}{c}\text { Ad } \\
\text { Instances }\end{array}$}} & \multicolumn{5}{|c|}{ Ad Instances by Mood } & \multicolumn{6}{|c|}{ Unique Ad Creatives by Mood } & \multicolumn{2}{|c|}{$\begin{array}{c}\text { Ad Instances by } \\
\text { Content }\end{array}$} \\
\hline & & & & & & Active & ive Emo & tional & Funny I & Informational & Sexy & Active & Emotional & Funny Info & formational & 1 Sexy & Price & $\begin{array}{c}\text { Web } \\
\text { Address }\end{array}$ \\
\hline 1 & 1 & 3 & & \multicolumn{2}{|c|}{159} & \multicolumn{2}{|c|}{56} & 0 & 51 & 52 & 0 & 1 & 0 & 1 & 1 & 0 & 51 & 0 \\
\hline 2 & 19 & 45 & & \multicolumn{2}{|c|}{254} & \multicolumn{2}{|c|}{183} & 8 & 0 & 33 & 30 & 29 & 6 & 0 & 4 & 10 & 42 & 254 \\
\hline 3 & 1 & 1 & & \multicolumn{2}{|c|}{4} & \multicolumn{2}{|c|}{0} & 0 & 0 & 0 & 4 & 0 & 0 & 0 & 0 & 1 & 0 & 0 \\
\hline 4 & 4 & 10 & & \multicolumn{2}{|c|}{497} & \multicolumn{2}{|c|}{350} & 3 & 0 & 144 & 0 & 7 & 1 & 0 & 2 & 0 & 0 & 0 \\
\hline 5 & 12 & 27 & & \multicolumn{2}{|c|}{771} & \multicolumn{2}{|c|}{632} & 0 & 139 & 0 & 0 & 25 & 0 & 2 & 0 & 0 & 453 & 521 \\
\hline Total & 37 & 90 & & \multicolumn{2}{|c|}{1685} & \multicolumn{2}{|c|}{1221} & 11 & 190 & 229 & 34 & 62 & 7 & 3 & 7 & 11 & 546 & 775 \\
\hline & & Ad Instc & ances & by $\mathrm{Po}$ & sition & & & & & Mean (SD) & & & & & Onlir & $\overline{\text { ine Ad }}$ & dvertising & Spend \\
\hline Retailer & $\begin{array}{r}\text { Air Simultan } \\
\text { with Ads } \\
\text { Different Brc } \\
\text { Networ }\end{array}$ & $\begin{array}{l}\text { eously } \\
\text { on } \\
\text { oadcast } \\
\text { ck }\end{array}$ & $\begin{array}{l}\text { Air } \mathrm{W} \\
2 \mathrm{Mir} \\
\text { of a } \mathrm{I} \\
\text { hour } \mathrm{F}\end{array}$ & $\begin{array}{l}\text { vithin } \\
\text { nutes } \\
\text { Half- } \\
\text { Break }\end{array}$ & $\begin{array}{l}\text { Air } \\
\text { Seas } \\
\text { Premi }\end{array}$ & & $\begin{array}{c}\text { Air on } \\
\text { Fall } \\
\text { Finale }\end{array}$ & $\begin{array}{l}\text { Mea } \\
\text { Ad I }\end{array}$ & $\begin{array}{l}\text { n }(S D) \\
\text { Length }\end{array}$ & $\begin{array}{c}\text { Relative } \\
\text { Ad } \\
\text { Position in } \\
\text { Break }\end{array}$ & $\begin{array}{r}\text { Relat } \\
\text { Posit } \\
\text { Pro }\end{array}$ & $\begin{array}{l}\text { itive Ad } \\
\text { ition in } \\
\text { gram }\end{array}$ & $\begin{array}{r}\text { Mea } \\
\text { Audier }\end{array}$ & $\begin{array}{l}\text { n }(S D) \\
\text { nce Size }\end{array}$ & $\begin{array}{r}\text { Mean (SD } \\
\text { Internet } \\
\text { Display } \\
\text { Spend } \\
\end{array}$ & $\begin{array}{l}\text { D) } \mathrm{Me} \\
\mathrm{t}\end{array}$ & $\begin{array}{l}\text { lean (SD) } \\
\text { Internet } \\
\text { Search } \\
\text { Spend } \\
\end{array}$ & $\begin{array}{c}\text { Mean (SD) } \\
\text { Online } \\
\text { Video } \\
\text { Spend } \\
\end{array}$ \\
\hline 1 & 101 & & 1 & & 0 & & 27 & 30.0 & $0(0.00)$ & $0.44(0.25)$ & 0.61 & $1(0.28)$ & 3855676 & $5(2113129)$ & $7.26(0.73$ & 3) 8.3 & $34(0.77)$ & $5.14(0.77)$ \\
\hline 2 & 155 & & 3 & 3 & 15 & & 48 & 27.6 & $4(5.47)$ & $0.43(0.24)$ & 0.61 & $1(0.30)$ & 4621003 & 3 (2219827) & $6.84(0.71$ & 1) 7.1 & $14(0.76)$ & $5.03(0.70)$ \\
\hline 3 & 2 & & c & 0 & 0 & & 2 & 15.0 & $0(0.00)$ & $0.48(0.26)$ & 0.70 & $0(0.28)$ & 2926623 & $3(2027190)$ & $2.91(0.09$ & 9) 5.4 & $45(0.10)$ & $2.19(0.97)$ \\
\hline 4 & 303 & & 7 & 0 & 53 & & 41 & 31.9 & $9(7.72)$ & $0.40(0.25)$ & 0.61 & $1(0.29)$ & 4347645 & $5(2322957)$ & $6.22(0.80$ & & $.74(0.82)$ & $4.29(0.82)$ \\
\hline 5 & 491 & & 8 & 6 & 121 & & 62 & 30.0 & $0(4.19)$ & $0.43(0.26)$ & 0.60 & $0(0.32)$ & 4507512 & $2(2356638)$ & $7.91(0.79$ & & $46(0.80)$ & $5.97(0.91)$ \\
\hline Total & 1052 & & 20 & 02 & 185 & & 180 & 30.2 & $0(5.71)$ & $0.42(0.25)$ & 0.60 & $0(0.30)$ & 4412205 & $5(2311238)$ & $7.18(1.08$ & & $.28(0.92)$ & $5.24(1.12)$ \\
\hline
\end{tabular}

Note: Table 5 provides description of the variables. Frequency of ad instances by the retailers across program genre and network as well as the frequency of ad instances across time of day, day of the week, and month are shown in Tables A2 and A3 in the Online Appendix. 
Table 2: Descriptive Statistics for Retailers' Advertisements and Online Retailer Mentions

\begin{tabular}{|c|c|c|c|c|c|c|c|c|c|c|c|c|}
\hline \multirow[b]{2}{*}{ Retailer } & \multirow{2}{*}{$\begin{array}{c}\text { Mean }(S D) \\
\text { Retailer } \\
\text { Mentions within } \\
5 \text { Minutes of Ad } \\
\text { Airing }\end{array}$} & \multicolumn{5}{|c|}{$\begin{array}{l}\text { Retailer Mentions within } 5 \text { Minutes of Ad } \\
\text { Airing }\end{array}$} & \multirow{2}{*}{$\begin{array}{c}\text { Mean }(S D) \\
\text { Percentage Change } \\
\text { in Retailer } \\
\text { Mentions }\end{array}$} & \multicolumn{5}{|c|}{ Percentage Change in Retailer Mentions } \\
\hline & & Min & $\begin{array}{c}1^{\text {st }} \\
\text { Quartile }\end{array}$ & Median & $\begin{array}{c}3^{\text {rd }} \\
\text { Quartile }\end{array}$ & Max & & Min & $\begin{array}{c}1^{\text {st }} \\
\text { Quartile }\end{array}$ & Median & $\begin{array}{c}3^{\text {rd }} \\
\text { Quartile }\end{array}$ & Max \\
\hline 1 & $39.25(19.21)$ & 17 & 31 & 36 & 43 & 170 & $5.93 \%(30.69 \%)$ & $-46.48 \%$ & $-16.90 \%$ & $2.00 \%$ & $9 \%$ & $114.71 \%$ \\
\hline 2 & $12.57(9.52)$ & 0 & 7 & 10 & 15 & 69 & $26.30 \%(80.21 \%)$ & $-91.67 \%$ & $-22.60 \%$ & $0.00 \%$ & $57.14 \%$ & $425.00 \%$ \\
\hline 3 & $32.75(5.32)$ & 27 & 29 & 33 & 36 & 39 & $6.94 \%(23.51 \%)$ & $-20.51 \%$ & $-7.16 \%$ & $7.47 \%$ & $21.57 \%$ & $33.33 \%$ \\
\hline 4 & $40.27(10.34)$ & 15 & 35 & 39 & 45 & 140 & $1.63 \%(26.18 \%)$ & $-56.72 \%$ & $-15.56 \%$ & $-2.50 \%$ & $17.31 \%$ & $227.91 \%$ \\
\hline 5 & $28.21(9.65)$ & 8 & 22 & 27 & 33 & 90 & $5.77 \%(38.16 \%)$ & $-70.45 \%$ & $-20.00 \%$ & $2.86 \%$ & $24.19 \%$ & $480.00 \%$ \\
\hline All Data & $30.46(14.44)$ & 0 & 22 & 30 & 39 & 170 & $7.66 \%(44.60 \%)$ & $-91.67 \%$ & $-18.18 \%$ & $0.00 \%$ & $23.08 \%$ & $480.00 \%$ \\
\hline
\end{tabular}

Note: Percentage change in retailer mentions for these descriptive statistics is calculated as (number of retailer mentions in 5 minutes post-ad airing - number of retailer mentions in 5 minutes pre-ad airing)/(number of retailer mentions in 5 minutes pre-ad airing +1$)$.

\section{Table 3: Descriptive Statistics for Retailers' Advertisements and Online Program Mentions}

\begin{tabular}{|c|c|c|c|c|c|c|c|c|c|c|c|c|}
\hline \multirow[b]{2}{*}{ Retailer } & \multirow{2}{*}{$\begin{array}{c}\text { Mean }(S D) \\
\text { Program } \\
\text { Mentions Per } \\
\text { Minute Up Until } \\
\text { Ad Airing }\end{array}$} & \multicolumn{5}{|c|}{$\begin{array}{c}\text { Program Mentions Per Minute Up Until Ad } \\
\text { Airing }\end{array}$} & \multirow{2}{*}{$\begin{array}{c}\text { Mean }(S D) \text { Program } \\
\text { Mentions in the } \\
\text { Minute before Ad } \\
\text { Airing }\end{array}$} & \multicolumn{5}{|c|}{$\begin{array}{c}\text { Program Mentions in the Minute before Ad } \\
\text { Airing }\end{array}$} \\
\hline & & Min & $\begin{array}{c}1^{\text {st }} \\
\text { Quartile }\end{array}$ & Median & $\begin{array}{c}3^{\text {rd }} \\
\text { Quartile }\end{array}$ & Max & & Min & $\begin{array}{c}1^{\text {st }} \\
\text { Quartile }\end{array}$ & Median & $\begin{array}{c}3^{\text {rd }} \\
\text { Quartile }\end{array}$ & Max \\
\hline 1 & $238.57(368.41)$ & 0 & 45 & 108 & 315 & 3414 & $430.69(2244.71)$ & 0 & 44 & 111 & 329 & 27870 \\
\hline 2 & $294.14(644.16)$ & 2 & 48 & 135 & 297 & 7669 & $307.61(746.35)$ & 1 & 42 & 133 & 308 & 10310 \\
\hline 3 & $1163.74(1641.46)$ & 266 & 347 & 382 & 1199 & 3625 & $1332.25(2088.99)$ & 190 & 300 & 338 & 1370 & 4464 \\
\hline 4 & $301.41(511.48)$ & 0 & 55 & 159 & 340 & 5362 & $305.95(629.08)$ & 0 & 50 & 129 & 333 & 7867 \\
\hline 5 & $266.66(442.20)$ & 1 & 44 & 119 & 319 & 5223 & $258.39(437.40)$ & 0 & 39 & 105 & 309 & 5319 \\
\hline All Data & $280.53(498.60)$ & 0 & 48 & 131 & 321 & 7669 & $298.65(879.33)$ & 0 & 44 & 116 & 323 & 27870 \\
\hline
\end{tabular}

Note: Program mentions per minute up until ad airing is the volume of Twitter mentions about the program from the beginning of the episode in which a given ad airs up until the ad airs divided by the number of minutes in that time window. Program mentions in the minute before ad airing is the volume of program mentions in the one-minute time window before an ad airs. 
Table 4: Descriptive Statistics for Retailers' Advertisements and Online Shopping

\begin{tabular}{|c|c|c|c|c|c|c|c|c|c|c|}
\hline \multirow{2}{*}{ Retailer } & \multirow{2}{*}{\multicolumn{2}{|c|}{$\begin{array}{c}\text { Ad Insertions with } \\
\text { Web Sessions within } 5 \\
\text { Minutes of Ad Airing }\end{array}$}} & \multirow{2}{*}{\multicolumn{2}{|c|}{$\begin{array}{l}\text { Ad Insertions that } \\
\text { Increase Web } \\
\text { Sessions within } 5 \\
\text { Minutes of Ad } \\
\text { Airing }\end{array}$}} & \multirow{3}{*}{$\begin{array}{c}\text { Mean Percentage } \\
\text { Change in Web } \\
\text { Sessions from } 5 \\
\text { Minutes Pre-ad to } 5 \\
\text { Minutes Post-ad } \\
6.09 \%(53.11 \%)\end{array}$} & \multicolumn{5}{|c|}{$\begin{array}{c}\text { Percentage Change in Web Sessions from } 5 \text { Minutes Pre- } \\
\text { ad to } 5 \text { Minutes Post-ad }\end{array}$} \\
\hline & & & & & & Min & $1^{\text {st }}$ Quartile & Median & $3^{\text {rd }}$ Quartile & Max \\
\hline 1 & 159 & $100.00 \%$ & 68 & $42.77 \%$ & & $-78.57 \%$ & $-25.00 \%$ & $-6.25 \%$ & $31.67 \%$ & $400.00 \%$ \\
\hline 2 & 131 & $51.57 \%$ & 76 & $29.92 \%$ & $21.09 \%(87.16 \%)$ & $-83.33 \%$ & $-50.00 \%$ & $0.00 \%$ & $100.00 \%$ & $400.00 \%$ \\
\hline 3 & 1 & $25.00 \%$ & 1 & $25.00 \%$ & $25.00 \%(50.00 \%)$ & $0.00 \%$ & $0.00 \%$ & $0.00 \%$ & $25.00 \%$ & $100.00 \%$ \\
\hline 4 & 490 & $98.59 \%$ & 190 & $38.23 \%$ & $12.55 \%(79.04 \%)$ & $-87.50 \%$ & $-33.33 \%$ & $0.00 \%$ & $33.33 \%$ & $450.00 \%$ \\
\hline 5 & 723 & $93.77 \%$ & 326 & $42.28 \%$ & $27.23 \%(93.83 \%)$ & $-90.00 \%$ & $-33.33 \%$ & $0.00 \%$ & $60.00 \%$ & $600.00 \%$ \\
\hline All Data & 1504 & $89.26 \%$ & 661 & $39.23 \%$ & $19.97 \%(85.65 \%)$ & $-90.00 \%$ & $-33.33 \%$ & $0.00 \%$ & $50.00 \%$ & $600.00 \%$ \\
\hline
\end{tabular}

\begin{tabular}{|c|c|c|c|c|c|c|c|c|c|}
\hline \multirow[t]{2}{*}{ Retailer } & \multirow{2}{*}{\multicolumn{2}{|c|}{$\begin{array}{c}\text { Ad Insertions with } \\
\text { Web Sessions within } 5 \\
\text { minutes of Ad Airing } \\
\text { that Generate } \\
\text { Transactions in the } \\
\text { Next } 24 \text { Hours }\end{array}$}} & \multirow{2}{*}{$\begin{array}{c}\text { Mean Percentage } \\
\text { Change in Purchases } \\
\text { from } 5 \text { minutes Pre-ad } \\
\text { to } 5 \text { minutes Post-ad }\end{array}$} & $\begin{array}{r}\text { Percenta } \\
\text { mint }\end{array}$ & $\begin{array}{r}\text { Change } i \\
\text { s Post-ad } \\
\text { co }\end{array}$ & $\begin{array}{l}\text { urchases } \\
\text { counting } \\
\text { deration }\end{array}$ & $\begin{array}{l}\text { m } 5 \text { minut } \\
\text { 24-hour } 1 \\
\text { dow) }\end{array}$ & $\begin{array}{l}\text { Pre-ad to } 5 \\
\text { rchase }\end{array}$ & \multirow{2}{*}{$\begin{array}{c}\text { Conversion } \\
\text { Rate }\end{array}$} \\
\hline & & & & Min & $\begin{array}{c}1^{\text {st }} \\
\text { Quartile }\end{array}$ & Median & $\begin{array}{c}3^{\text {rd }} \\
\text { Quartile }\end{array}$ & $\operatorname{Max}$ & \\
\hline 1 & 131 & $82.39 \%$ & $96.48 \%(178.54 \%)$ & $-80.00 \%$ & $0.00 \%$ & $50.00 \%$ & $150.00 \%$ & $1300.00 \%$ & $18.59 \%$ \\
\hline 2 & 9 & $3.54 \%$ & $17.87 \%(228.85 \%)$ & $-80.00 \%$ & $0.00 \%$ & $0.00 \%$ & $0.00 \%$ & $3600.00 \%$ & $25.38 \%$ \\
\hline 3 & 0 & $0.00 \%$ & $0.00 \%(0.00 \%)$ & $0.00 \%$ & $0.00 \%$ & $0.00 \%$ & $0.00 \%$ & $0.00 \%$ & $0.00 \%$ \\
\hline 4 & 1 & $0.20 \%$ & $0.00 \%(5.50 \%)$ & $-50.00 \%$ & $0.00 \%$ & $0.00 \%$ & $0.00 \%$ & $100.00 \%$ & $0.04 \%$ \\
\hline 5 & 1 & $0.13 \%$ & $0.00 \%(4.41 \%)$ & $-50.00 \%$ & $0.00 \%$ & $0.00 \%$ & $0.00 \%$ & $100.00 \%$ & $0.05 \%$ \\
\hline All Data & 142 & $8.43 \%$ & $11.80 \%(108.00 \%)$ & $-80.00 \%$ & $0.00 \%$ & $0.00 \%$ & $0.00 \%$ & $3600.00 \%$ & $5.83 \%$ \\
\hline
\end{tabular}

Absolute Change in Web Sessions from 5 Minutes Pre-ad to 5 Absolute Change in Purchases from 5 Minutes Pre-ad to 5

\begin{tabular}{|c|c|c|c|c|c|c|c|c|c|c|}
\hline & \multicolumn{4}{|c|}{ Minutes Post-ad } & \multicolumn{6}{|c|}{ Minutes Post-ad } \\
\hline & Min & $1^{\text {st }}$ Quartile & Median & $3^{\text {rd }}$ Quartile & Max & Min & $1^{\text {st }}$ Quartile & Median & $3^{\text {rd }}$ Quartile & Max \\
\hline All Data & -17 & -2 & 0 & 2 & 13 & -4 & 0 & 0 & 0 & 36 \\
\hline
\end{tabular}

Note: Percentage changes are calculated as (activity in post-ad window - activity in pre-ad window)/(activity in pre-ad window +1$)$. For the change in purchases post-ad, we use the number of web sessions within 5 minutes of an ad's airing that generate transactions in the next 24 hours. $39 \%$ ( $8 \%$ ) of ad instances see a positive change in web traffic (online purchases), while $42 \%$ (2\%) of ad instances see a negative change in web traffic (online purchases). Conversion rate is calculated as (number of web sessions initiated within 5 minutes of an ad's airing that generated a transaction in the next 24 hours)/(number of web sessions initiated within 5 minutes of an ad's airing). If we exclude the purchase consideration window and look at the percentage change in purchases from 5 minutes pre-ad to 5 minutes post-ad, we see that the mean (SD) percentage change in purchases is $3.71 \%(36.41 \%)$. 
Table 5: Summary of Variables in $X_{i k}$

\begin{tabular}{|c|c|c|}
\hline Parameter & Variable & Description \\
\hline $\begin{array}{l}\text { Ad break } \\
\text { position in } \\
\text { program }\end{array}$ & $X_{i l}$ & $\begin{array}{l}\text { Relative ad break position in program, calculated as (position of the ad break in } \\
\text { the program)/(number of ad breaks in the program) }\end{array}$ \\
\hline Ad length & $X_{i 2}$ & Ad length in seconds \\
\hline \multirow[t]{2}{*}{ Ad mood } & $X_{i 3}-X_{i 6}$ & $\begin{array}{l}\text { Dummy variables for ad mood: active, emotional, information, or sexy (Baseline } \\
\text { funny) }\end{array}$ \\
\hline & $X_{i 7}-X_{i 22}$ & $\begin{array}{l}\text { Interactions of ad mood variables with } \log P W O M V o l u m e_{i}, \log P W O M V o l u m e_{i}{ }^{2} \text {, } \\
\text { PWOMChange } e_{i} \text {, and PWOMChange }{ }_{i}{ }^{2} \text { (defined below) }\end{array}$ \\
\hline $\begin{array}{l}\text { Ads on other } \\
\text { networks }\end{array}$ & $X_{i 23}$ & $\begin{array}{l}\text { Dummy variable if an ad runs simultaneously with another ad break on a } \\
\text { different broadcast network }\end{array}$ \\
\hline $\begin{array}{l}\text { Ad position in ad } \\
\text { break }\end{array}$ & $X_{i 24}$ & $\begin{array}{l}\text { Relative ad position in the ad break, calculated as (position of the ad in the ad } \\
\text { break)/(number of ads in the ad break) }\end{array}$ \\
\hline Audience size & $X_{i 25}$ & Log of the number of households tuned into a program when ad $i$ airs \\
\hline Day & $X_{i 26}-X_{i 31}$ & Dummy variables for day of the week ad airs (Baseline: Friday) \\
\hline Half-hour break & $X_{i 32}$ & Dummy variable for if ad airs within two minutes of a half-hour break \\
\hline Month & $X_{i 33}-X_{i 35}$ & $\begin{array}{l}\text { Dummy variables for month ad airs: September, October, or November } \\
\text { (Baseline: December) }\end{array}$ \\
\hline $\begin{array}{l}\text { Online } \\
\text { Advertising } \\
\text { Spend }\end{array}$ & $X_{i 36}-X_{i 38}$ & $\begin{array}{l}\text { Internet display spend, internet search spend, and online video spend by the } \\
\text { brand in ad } i \text { in the month ad } i \text { airs. We weight this measure by the number of } \\
\text { days that have passed in a given month before ad } i \text { airs. For example, if ad } i \text { airs } \\
\text { on Dec. 15th, these measures are multiplied by } \frac{15}{31} \text {. We then take the log of these } \\
\text { measures plus one. }\end{array}$ \\
\hline $\begin{array}{l}\text { Online program } \\
\text { engagement: } \\
\text { Volume }\end{array}$ & $X_{i 39}-X_{i 40}$ & $\begin{array}{l}P W O M \text { olume }_{i} \text { is equal to the number of program mentions from the start of an } \\
\text { episode until ad } i \text { airs divided by the minutes in the episode up until ad } i \text { airs. We } \\
\text { take the log of this measure plus one to create LogPWOMVolume }{ }_{i} \text {. A quadratic } \\
\text { effect }\left(\text { LogPWOMVolume }_{i}^{2}\right) \text { is also included in } X_{i k} \text {. }\end{array}$ \\
\hline $\begin{array}{l}\text { Online program } \\
\text { engagement: } \\
\text { Change }\end{array}$ & $X_{i 41}-X_{i 42}$ & $\begin{array}{l}P W O M C h a n g e_{i} \text { is equal to the number of program mentions between one minute } \\
\text { before ad } i \text { airs until ad } i \text { airs divided by } P \text { WOMVolume } \\
\text {. A quadratic effect } \\
\left(P W O M C h a n g e_{i}^{2}\right) \text { is also included in } X_{i k} \text {. }\end{array}$ \\
\hline $\begin{array}{l}\text { Online retailer } \\
\text { mentions }\end{array}$ & $X_{i 43}-X_{i 44}$ & $\begin{array}{l}\text { Change in online retailer mentions for the retailer in ad } i \text { following ad } i \text { 's airing, } \\
\text { calculated as (number of retailer mentions between when ad } i \text { airs and five } \\
\text { minutes after ad } i \text { airs/number of retailer mentions between five minutes before } \\
\text { ad } i \text { airs until ad } i \text { airs }+1 \text { ). We take the log of this measure plus one. We include } \\
\text { both a linear and quadratic effect. }\end{array}$ \\
\hline Price & $X_{i 45}$ & Dummy variable for if the ad refers to price \\
\hline Special episodes & $X_{i 46}-X_{i 47}$ & Dummy variables for if the ad airs on season premiere or fall finales episodes \\
\hline Time & $X_{i 48}-X_{i 58}$ & $\begin{array}{l}\text { Dummy variables for time in quarter-hour increments from 8:00-10:59pm } \\
\text { (Baseline: 10:45-10:59pm) }\end{array}$ \\
\hline Web address & $X_{i 59}$ & Dummy variable for if the ad contains a web address \\
\hline
\end{tabular}

Note: We test an alternative operationalization of PWOMChange $e_{i}$ where we take the log of this measure plus one. We also test alternative operationalizations of the online advertising spending variables where we do not weight these measures by the number of days that have passed in a given month. The results from these alternative models do not different from the main model, and these alternative models do not improve model fit compared to the main model. 
Table 6: Impact of Ad Characteristics on Online Shopping Activity

\begin{tabular}{|c|c|c|c|c|c|c|c|c|c|c|}
\hline \multirow{3}{*}{$\begin{array}{l}\text { Variable } \\
\text { Ad length }\end{array}$} & \multicolumn{5}{|c|}{ Impact on Online Traffic } & \multicolumn{5}{|c|}{ Impact on Online Purchases } \\
\hline & \multicolumn{3}{|c|}{ P.M. (SD) } & \multicolumn{2}{|c|}{ Effect Size (SD) } & \multicolumn{2}{|c|}{ P.M. $(S D)$} & & \multicolumn{2}{|c|}{ Effect Size (SD) } \\
\hline & -0.00 & $(0.00)$ & & -2 & (2) & 0.00 & $(0.00)$ & & 0 & (1) \\
\hline Audience size & 0.01 & $(0.03)$ & & 12 & (27) & -0.01 & $(0.02)$ & & -12 & (16) \\
\hline Internet display spend & 0.02 & $(0.09)$ & & 16 & (89) & -0.07 & $(0.05)$ & & -69 & (45) \\
\hline Internet search spend & 0.01 & $(0.08)$ & & 9 & (81) & 0.07 & $(0.04)$ & * & 67 & $(41)$ \\
\hline Online retailer mentions & 0.66 & $(0.25)$ & ** & 898 & $(458)$ & -0.04 & $(0.14)$ & & -36 & (142) \\
\hline Online retailer mentions ${ }^{2}$ & -0.42 & $(0.15)$ & $* *$ & -493 & $(215)$ & 0.02 & $(0.09)$ & & 18 & $(84)$ \\
\hline Online video spend & -0.00 & $(0.03)$ & & -3 & (32) & 0.00 & $(0.02)$ & & 4 & (15) \\
\hline Price & 0.04 & $(0.04)$ & & 37 & (38) & 0.04 & $(0.02)$ & * & 36 & (19) \\
\hline Web address & 0.05 & $(0.06)$ & & 44 & (55) & 0.02 & $(0.03)$ & & 17 & (26) \\
\hline
\end{tabular}

Note: Posterior mean (P.M.) and standard deviation (SD) estimates are presented with double asterisks ** (single asterisk *) indicating that the 95\% (90\%) HPD interval excludes zero. To estimate effect size for U.S. population, we transform the posterior mean estimates at each iteration to account for our original log transformation and then extrapolate our findings from comScore's panel of 100,000 U.S internet users to the number of U.S. households with internet in 2013 (91,109,500).

Table 7: Impact of When Ads Air on Online Shopping Activity

\begin{tabular}{|c|c|c|c|c|c|c|c|c|c|c|}
\hline \multirow{3}{*}{$\begin{array}{l}\text { Variable } \\
\text { Ad break position in program }\end{array}$} & \multicolumn{5}{|c|}{ Impact on Online Traffic } & \multicolumn{5}{|c|}{ Impact on Online Purchases } \\
\hline & \multicolumn{3}{|c|}{ P.M. (SD) } & \multicolumn{2}{|c|}{ Effect Size (SD) } & \multicolumn{3}{|c|}{ P.M. (SD) } & \multicolumn{2}{|c|}{ Effect Size $(S D)$} \\
\hline & 0.08 & $(0.07)$ & & 81 & $(67)$ & 0.00 & $(0.04)$ & & 2 & (33) \\
\hline Ad position in ad break & -0.03 & $(0.05)$ & & -29 & $(46)$ & 0.00 & $(0.02)$ & & 4 & $(22)$ \\
\hline Ads on other network & -0.00 & $(0.02)$ & & -1 & $(23)$ & 0.02 & $(0.01)$ & & 15 & $(11)$ \\
\hline \multicolumn{11}{|l|}{ Day (Baseline: Friday) } \\
\hline Monday & 0.19 & $(0.06)$ & $* *$ & 191 & $(66)$ & -0.01 & $(0.04)$ & & -11 & (37) \\
\hline Tuesday & 0.22 & $(0.06)$ & $* *$ & 227 & $(69)$ & -0.04 & $(0.04)$ & & -34 & $(41)$ \\
\hline Wednesday & 0.12 & $(0.06)$ & * & 116 & $(65)$ & 0.01 & $(0.04)$ & & 7 & $(35)$ \\
\hline Thursday & 0.10 & $(0.06)$ & & 94 & $(61)$ & -0.01 & $(0.04)$ & & -8 & $(34)$ \\
\hline Saturday & -0.36 & $(0.22)$ & * & -419 & (291) & 0.06 & $(0.13)$ & & 58 & $(131)$ \\
\hline Sunday & 0.13 & $(0.07)$ & * & 124 & $(68)$ & 0.01 & $(0.04)$ & & 5 & (38) \\
\hline Fall finale & -0.08 & $(0.05)$ & & -73 & $(51)$ & -0.06 & $(0.03)$ & $* *$ & -58 & $(25)$ \\
\hline Half-hour break & -0.02 & $(0.04)$ & & -21 & (35) & 0.04 & $(0.02)$ & $* *$ & 41 & $(17)$ \\
\hline \multicolumn{11}{|l|}{ Month } \\
\hline September & -0.08 & $(0.07)$ & & -78 & (73) & -0.03 & $(0.04)$ & & -29 & $(36)$ \\
\hline October & -0.14 & $(0.06)$ & $* *$ & -136 & $(65)$ & 0.01 & $(0.04)$ & & 9 & (33) \\
\hline November & -0.12 & $(0.06)$ & * & -119 & $(64)$ & -0.01 & $(0.03)$ & & -8 & $(32)$ \\
\hline Season premiere & 0.03 & $(0.05)$ & & 25 & $(48)$ & 0.01 & $(0.03)$ & & 9 & $(23)$ \\
\hline \multicolumn{11}{|l|}{ Time (Baseline: 10:45-10:59pm) } \\
\hline $8: 00-8: 14 \mathrm{pm}$ & 0.35 & $(0.09)$ & $* *$ & 381 & $(110)$ & -0.05 & $(0.06)$ & & -52 & $(59)$ \\
\hline $8: 15-8: 29 \mathrm{pm}$ & 0.29 & $(0.07)$ & $* *$ & 315 & $(89)$ & -0.04 & $(0.05)$ & & -35 & $(49)$ \\
\hline $8: 30-8: 44 \mathrm{pm}$ & 0.20 & $(0.07)$ & $* *$ & 202 & $(77)$ & -0.01 & $(0.04)$ & & -12 & $(41)$ \\
\hline $8: 45-8: 59 \mathrm{pm}$ & 0.22 & $(0.07)$ & $* *$ & 223 & $(75)$ & -0.03 & $(0.04)$ & & -29 & $(40)$ \\
\hline 9:00-9:14pm & 0.29 & $(0.08)$ & $* *$ & 313 & (98) & -0.03 & $(0.05)$ & & -30 & $(52)$ \\
\hline 9:15-9:29pm & 0.19 & $(0.07)$ & $* *$ & 191 & (78) & -0.04 & $(0.04)$ & & -40 & (41) \\
\hline 9:30-9:44pm & 0.11 & $(0.07)$ & & 103 & $(68)$ & -0.02 & $(0.04)$ & & -20 & $(35)$ \\
\hline 9:45-9:59pm & 0.11 & $(0.06)$ & $*$ & 111 & (66) & -0.02 & $(0.04)$ & & -16 & (34) \\
\hline 10:00-10:14pm & 0.24 & $(0.08)$ & $* *$ & 247 & (96) & 0.01 & $(0.05)$ & & 13 & (46) \\
\hline $10: 15-10: 29 \mathrm{pm}$ & 0.09 & $(0.08)$ & & 89 & (76) & -0.02 & $(0.04)$ & & -16 & (36) \\
\hline $10: 30-10: 44 \mathrm{pm}$ & 0.07 & $(0.07)$ & & 69 & $(71)$ & 0.01 & $(0.04)$ & & 10 & (34) \\
\hline
\end{tabular}

Note: Posterior mean (P.M.) and standard deviation (SD) estimates are presented with double asterisks ** (single asterisk

*) indicating that the 95\% (90\%) HPD interval excludes zero. See the note under Table 6 about effect size. 
Table 8: Impact of Ad Mood and Online Program Engagement on Online Shopping Activity

\begin{tabular}{|c|c|c|c|c|c|c|c|c|}
\hline \multirow{3}{*}{$\begin{array}{l}\text { Variable } \\
\text { Ad mood (Baseline: Funny) }\end{array}$} & \multicolumn{3}{|c|}{ Impact on Online Traffic } & \multicolumn{5}{|c|}{ Impact on Online Purchases } \\
\hline & \multirow[t]{2}{*}{ P.M. (SD) } & \multicolumn{2}{|c|}{ Effect Size (SD) } & \multicolumn{3}{|c|}{$P . M .(S D)$} & \multicolumn{2}{|c|}{ Effect Size $(S D)$} \\
\hline & & & & & & & & \\
\hline Active & $-0.34(0.35)$ & -438 & (493) & 0.37 & $(0.21)$ & & 443 & (292) \\
\hline Emotional & $-3.03(2.06)$ & -203024 & (1439396) & 0.51 & (1.45) & & 2399 & (19100) \\
\hline Informational & $-0.06(0.40)$ & -75 & $(521)$ & 0.51 & $(0.23)$ & $* *$ & 649 & $(362)$ \\
\hline Sexy & $-0.86(1.48)$ & -5228 & (16596) & 0.40 & $(0.83)$ & & 833 & $(2042)$ \\
\hline \multicolumn{9}{|l|}{ Online program engagement } \\
\hline LogPWOMVolume $_{i}$ & $-0.02(0.12)$ & -21 & (122) & 0.24 & $(0.08)$ & $* *$ & 250 & (93) \\
\hline LogPWOMVolume $_{i}^{2}$ & $0.00(0.01)$ & 2 & (11) & -0.02 & $(0.01)$ & $* *$ & -21 & (7) \\
\hline LogPWOMVolume $_{i} *$ Active & $-0.00(0.12)$ & -1 & (125) & -0.24 & $(0.08)$ & $* *$ & -251 & (96) \\
\hline LogPWOMVolume $_{i}^{2} *$ Active & $0.00(0.01)$ & 0 & (11) & 0.02 & $(0.01)$ & $* *$ & 21 & (8) \\
\hline LogPWOMVolume $_{i} *$ Informational & $-0.10(0.15)$ & -103 & $(161)$ & -0.32 & $(0.09)$ & $* *$ & -343 & (115) \\
\hline LogPWOMVolume $_{i}{ }^{2} *$ Informational & $0.01 \quad(0.02)$ & 13 & $(15)$ & 0.03 & $(0.01)$ & $* *$ & 29 & (9) \\
\hline LogPWOMVolume $_{i} *$ Emotional & $1.91(0.81) * *$ & 7711 & (8669) & -0.47 & $(0.52)$ & & -744 & (1010) \\
\hline LogPWOMVolume $_{i}^{2} *$ Emotional & $-0.20(0.08) * *$ & -200 & $(85)$ & 0.05 & $(0.05)$ & & 45 & $(48)$ \\
\hline LogPWOMVolume $_{i} *$ Sexy & $0.04(0.48)$ & 64 & (680) & -0.29 & $(0.26)$ & & -343 & (337) \\
\hline LogPWOMVolume $_{i}{ }^{2} *$ Sexy & $-0.01(0.05)$ & -6 & (44) & 0.03 & $(0.03)$ & & 27 & (24) \\
\hline PWOMChange $_{i}$ & $-0.37(0.34)$ & -490 & (515) & -0.48 & $(0.19)$ & $* *$ & -592 & (275) \\
\hline PWOMChange $_{i}^{2}$ & $0.12(0.14)$ & 131 & (153) & 0.29 & $(0.08)$ & $* *$ & 307 & (94) \\
\hline PWOMChangei $*$ Active & $0.47(0.34)$ & 638 & (567) & 0.48 & $(0.19)$ & $* *$ & 587 & (277) \\
\hline PWOMChange $_{i}{ }^{2} *$ Active & $-0.13(0.14)$ & -136 & (154) & -0.29 & $(0.08)$ & $* *$ & -311 & (94) \\
\hline PWOMChange $i$ *Informational & $0.25(0.36)$ & 329 & (487) & 0.49 & $(0.19)$ & $* *$ & 598 & (282) \\
\hline PWOMChange $_{i}^{2} *$ Informational & $-0.11(0.14)$ & -120 & (153) & -0.29 & $(0.08)$ & $* *$ & -308 & (94) \\
\hline PWOMChangei $*$ Emotional & $-1.74(2.49)$ & -111089 & $(1027506)$ & 1.02 & (2.39) & & 20760 & (218546) \\
\hline PWOMChange $_{i}{ }^{2} *$ Emotional & $-0.15(1.72)$ & -796 & (20923) & -0.43 & (1.62) & & -2064 & (16476) \\
\hline PWOMChangei $*$ Sexy & $1.26(1.52)$ & 9183 & (30342) & 0.50 & $(0.88)$ & & 1152 & $(2804)$ \\
\hline PWOMChange $_{i}^{2} *$ Sexy & $-0.46(0.67)$ & -825 & $(1454)$ & -0.29 & $(0.38)$ & & -377 & $(562)$ \\
\hline Web address & $0.05(0.06)$ & 44 & $(55)$ & 0.02 & $(0.03)$ & & 17 & (26) \\
\hline
\end{tabular}

Note: Posterior mean (P.M.) and standard deviation (SD) estimates are presented with double asterisks ** (single asterisk *) indicating that the $95 \%$ (90\%) HPD interval excludes zero. The posterior mean estimates for LogPWOMVolume LogPWOMVolume $_{i}{ }^{2}$ PWOMChange ${ }_{i}$, and PWOMChange ${ }_{i}{ }^{2}$ capture the relationship between online program engagement and the online shopping measures for the baseline ad mood category (funny mood). See the note under Table 6 about effect size. 
Table 9: Impact of Viewers' Online Program Engagement on Online Traffic across Ad Mood (Baseline: Funny Advertisements)

Baseline Mood Category: Funny Advertisements

\begin{tabular}{|c|c|c|c|c|}
\hline PWOMChange $_{i}$ & 0.5 & 1.0 & 1.5 & 2.0 \\
\hline \multirow{2}{*}{$\begin{array}{l}\text { PWOMVolume }_{i} \\
1^{1 \text { st }} \text { Quartile }\end{array}$} & P.M. (SD) & P.M. (SD) & P.M. (SD) & P.M. (SD) \\
\hline & $\begin{array}{ll}-0.21 \quad(0.31) \\
\end{array}$ & $\begin{array}{ll}-0.30(0.34) \\
\end{array}$ & $-0.33 \quad(0.36)$ & $-0.30 \quad(0.36)$ \\
\hline Median & $-0.21 \quad(0.33)$ & $-0.31 \quad(0.36)$ & $-0.34 \quad(0.37)$ & $-0.30 \quad(0.38)$ \\
\hline $3^{\text {rd }}$ Quartile & $-0.21 \quad(0.33)$ & $-0.31 \quad(0.36)$ & $-0.34 \quad(0.37)$ & $-0.31 \quad(0.38)$ \\
\hline
\end{tabular}

Effects Relative to Baseline Mood Category: Funny Advertisements

Active Advertisements

\begin{tabular}{|c|c|c|c|c|}
\hline PWOMChange $_{i}$ & 0.5 & 1.0 & 1.5 & 2.0 \\
\hline PWOMVolume $_{i}$ & P.M. (SD) & P.M. (SD) & P.M. (SD) & P.M. (SD) \\
\hline $1^{\text {st }}$ Quartile & $-0.14 \quad(0.08)$ & $0.00 \quad(0.07)$ & $0.07 \quad(0.09)$ & $0.08 \quad(0.16)$ \\
\hline Median & $-0.13(0.08) *$ & $0.00 \quad(0.06)$ & $0.08 \quad(0.08)$ & $0.08 \quad(0.15)$ \\
\hline $3^{\text {rd }}$ Quartile & $-0.13 \quad(0.08)$ & $0.00 \quad(0.06)$ & $0.08 \quad(0.08)$ & $0.09 \quad(0.15)$ \\
\hline
\end{tabular}

Emotional Advertisements

\begin{tabular}{|c|c|c|c|c|}
\hline PWOMChange $_{i}$ & 0.5 & 1.0 & 1.5 & 2.0 \\
\hline PWOMVolume ${ }_{i}$ & P.M. (SD) & P.M. $(S D)$ & P.M. (SD) & P.M. (SD) \\
\hline $1^{\text {st }}$ Quartile & $0.54(0.31) *$ & $-0.44 \quad(0.34)$ & $-1.50(1.38)$ & $-2.62 \quad(3.27)$ \\
\hline Median & $0.73 \quad(0.37) * *$ & $-0.25 \quad(0.33)$ & -1.30 & $-2.43 \quad(3.26)$ \\
\hline $3^{\text {rd }}$ Quartile & $0.58 \quad(0.40)$ & $-0.40 \quad(0.32)$ & $-1.45 \quad(1.35)$ & $-2.58 \quad(3.25)$ \\
\hline
\end{tabular}

Informational Advertisements

\begin{tabular}{|c|c|c|c|c|}
\hline PWOMChange $_{i}$ & 0.5 & 1.0 & 1.5 & 2.0 \\
\hline PWOMVolume $_{i}$ & P.M. (SD) & P.M. (SD) & P.M. (SD) & P.M. (SD) \\
\hline $1^{\text {st }}$ Quartile & $-0.14 \quad(0.11)$ & $-0.09 \quad(0.08)$ & $-0.11 \quad(0.11)$ & $-0.18 \quad(0.17)$ \\
\hline Median & $-0.11 \quad(0.10)$ & $-0.07 \quad(0.07)$ & $-0.09 \quad(0.10)$ & $-0.16 \quad(0.17)$ \\
\hline $3^{\text {rd }}$ Quartile & $-0.07 \quad(0.11)$ & $-0.03 \quad(0.08)$ & $-0.04 \quad(0.10)$ & $-0.12 \quad(0.17)$ \\
\hline
\end{tabular}

Sexy Advertisements

\begin{tabular}{|c|c|c|c|c|}
\hline PWOMChange $_{i}$ & 0.5 & 1.0 & 1.5 & 2.0 \\
\hline PWOMVolume $_{i}$ & P.M. (SD) & P.M. (SD) & P.M. (SD) & P.M. (SD) \\
\hline $1^{\text {st }}$ Quartile & $-0.29(0.27)$ & $-0.00 \quad(0.16)$ & $0.06 \quad(0.27)$ & $-0.12(0.64)$ \\
\hline Median & $-0.30 \quad(0.28)$ & $-0.02 \quad(0.15)$ & $0.04 \quad(0.24)$ & $-0.13 \quad(0.62)$ \\
\hline $3^{\text {rd }}$ Quartile & $-0.33 \quad(0.30)$ & $-0.04 \quad(0.15)$ & $0.02 \quad(0.22)$ & $-0.16 \quad(0.61)$ \\
\hline
\end{tabular}

Note: Posterior mean (P.M.) and standard deviation (SD) estimates are presented with double asterisks $* *$ (single asterisk *) indicating that the 95\% (90\%) HPD interval excludes zero. Table 9 considers the combined impact of the measures of online program engagement without the log transformation. See footnote 22 for calculation of combined effect. Effects are relative to the baseline ad mood category (funny ads). 
Table 10: Impact of Viewers' Online Program Engagement on Online Purchases across Ad Mood (Baseline: Funny Advertisements)

Baseline Mood Category: Funny Advertisements

\begin{tabular}{|c|c|c|c|c|}
\hline$P W O N$ & 0.5 & 1.0 & 1.5 & 2.0 \\
\hline$P W C$ & P.M. (SD) & P.M. (SD) & P.M. (SD) & P.M. (SD) \\
\hline $1^{\text {st }} \mathrm{Q}$ & $0.41 \quad(0.20) * *$ & $0.38 \quad(0.21) * *$ & $0.50 \quad(0.22) * *$ & $0.76 \quad(0.22) * *$ \\
\hline & $0.45 \quad(0.21) * *$ & $0.42 \quad(0.22) * *$ & $0.54 \quad(0.23) * *$ & $0.80 \quad(0.23)$ \\
\hline $3^{\text {rd }}$ Quartile & $0.44 \quad(0.21) * *$ & $0.42 \quad(0.22) * *$ & $0.53(0.23) * *$ & $0.80 \quad(0.23) * *$ \\
\hline
\end{tabular}

Effects Relative to Baseline Mood Category: Funny Advertisements

Active Advertisements

\begin{tabular}{|c|c|c|c|c|}
\hline PWOMChange $_{i}$ & 0.5 & 1.0 & 1.5 & 2.0 \\
\hline PWOMVolume $_{i}$ & $P . M .(S D)$ & P.M. $(S D)$ & P.M. (SD) & P.M. (SD) \\
\hline $1^{\text {st }}$ Quartile & $-0.05 \quad(0.04)$ & $-0.03 \quad(0.03)$ & $-0.15 \quad(0.04) *$ & $-0.42 \quad(0.08) * *$ \\
\hline Median & $-0.09 \quad(0.04) * *$ & $-0.07 \quad(0.03) * *$ & $-0.19 \quad(0.04) * *$ & $-0.46(0.08) * *$ \\
\hline $3^{\text {rd }}$ Quartile & $-0.09 \quad(0.04) * *$ & $-0.07 \quad(0.03) * *$ & $-0.19 \quad(0.04) * *$ & $-0.46 \quad(0.07) * *$ \\
\hline
\end{tabular}

\section{Emotional Advertisements}

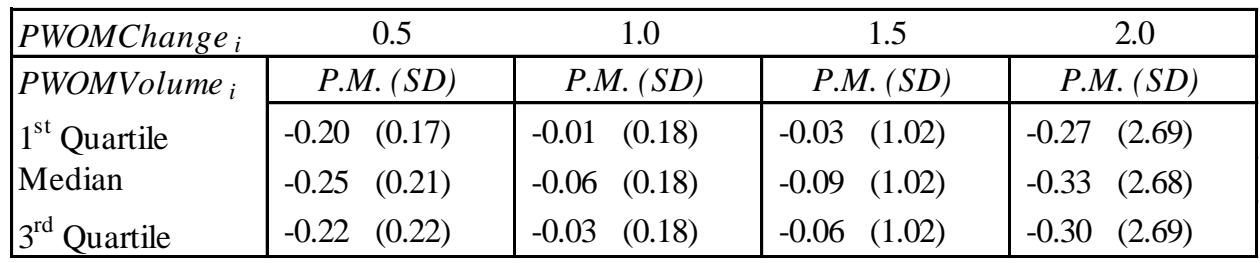

Informational Advertisements

\begin{tabular}{|c|c|c|c|c|}
\hline$P W O N$ & 0.5 & 1.0 & 1.5 & 2.0 \\
\hline$P W O P$ & P.M. ( & P.M. (SD) & P.M. (SD) & P.M. (SD) \\
\hline & $-0.07 \quad(0.0$ & $.05 \quad(0.04)$ & $-0.16(0.05) * *$ & $-0.42(0.08) * *$ \\
\hline & $-0.12(0.05) * *$ & $-0.09(0.04) * *$ & $-0.21 \quad(0.05) *$ & $-0.47(0.08) * *$ \\
\hline $3^{\text {rd }}$ Quartile & $-0.10 \quad(0.05) *$ & $-0.07 \quad(0.04) *$ & $-0.19(0.05) * *$ & $-0.45 \quad(0.08) * *$ \\
\hline
\end{tabular}

Sexy Advertis ements

\begin{tabular}{|c|c|c|c|c|}
\hline \multirow{2}{*}{$\begin{array}{l}\text { PWOMChange }_{i} \\
\text { PWOMVOlume }_{i}\end{array}$} & 0.5 & 1.0 & 1.5 & 2.0 \\
\hline & P.M. $(S D)$ & P.M. $(S D)$ & P.M. (SD) & P.M. $(S D)$ \\
\hline $1^{\text {st }} \mathrm{Ql}$ & $-0.11 \quad(0.15)$ & $-0.07 \quad(0.08)$ & $-0.18 \quad(0.13)$ & $-0.43 \quad(0.33)$ \\
\hline Median & $-0.15 \quad(0.15)$ & $-0.11 \quad(0.07)$ & $-0.22 \quad(0.12)$ & $-0.47 \quad(0.32)$ \\
\hline $3^{\text {rd }}$ Ouartile & $-0.14 \quad(0.16)$ & $-0.10 \quad(0.07)$ & $-0.21 \quad(0.11)$ & $-0.46 \quad(0.32)$ \\
\hline
\end{tabular}

Note: Posterior mean (P.M.) and standard deviation (SD) estimates are presented with double asterisks $* *$ (single asterisk *) indicating that the 95\% (90\%) HPD interval excludes zero. Table 10 considers the combined impact of the measures of online program engagement without the log transformation. See footnote 22 for calculation of combined effect. Effects are relative to the baseline ad mood category (funny ads). Figure 5 shows an illustration of the estimated effect sizes associated with these posterior mean estimates. 
Figure 1: Online Retailer Mentions and Web Traffic Retailer 1
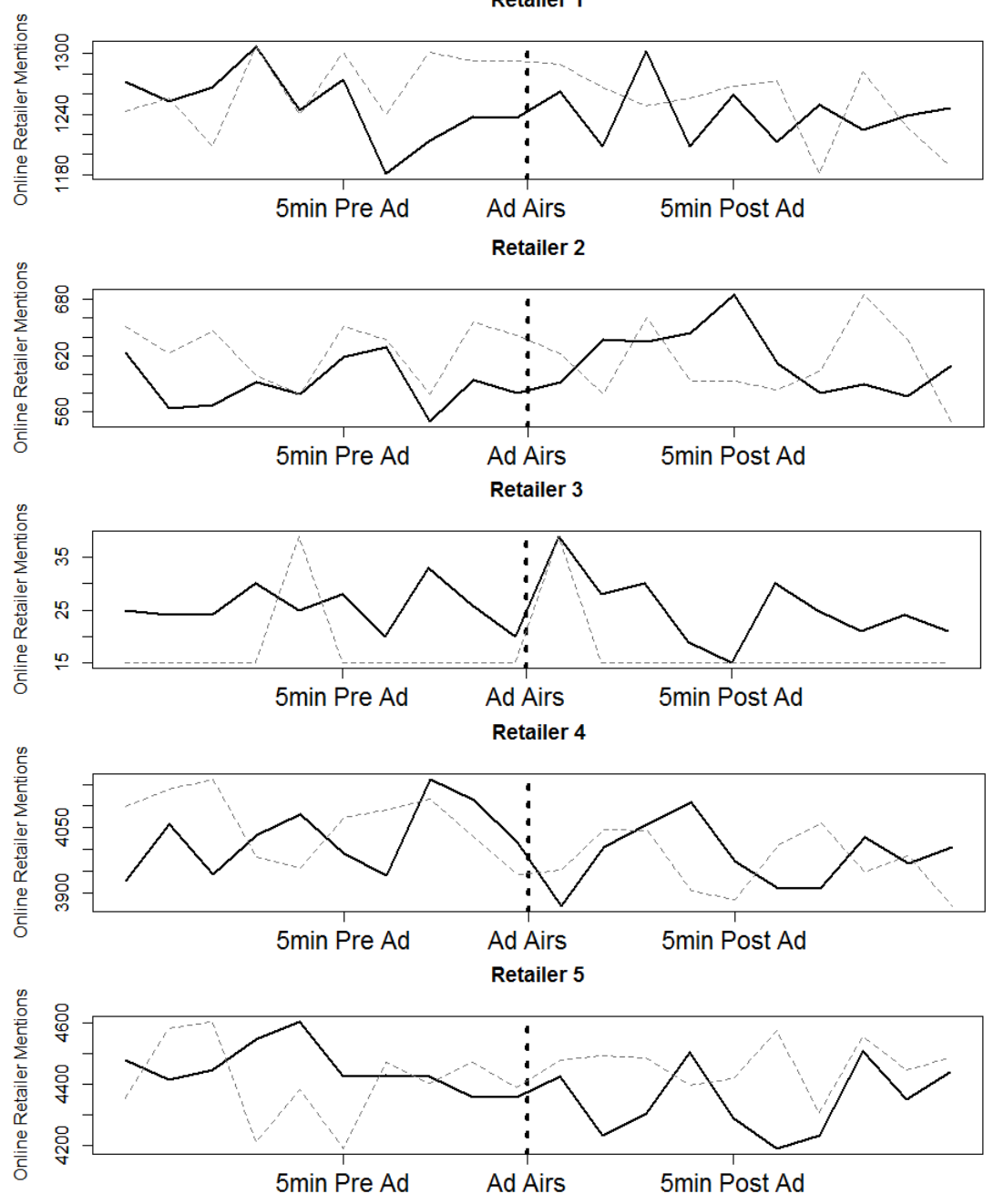

Note: Solid (dashed) line shows online retailer mentions (web traffic to the retailer's website). The y-axis is volume of online retailer mentions around the ads' airings summed across all ad instances for the retailer. Due to the data agreement with comScore, we cannot show volume for web sessions at the retailer-level, so this axis is excluded from Figure 1. Increases prior to the ads' airings is the result of the discrete time interpolation.
Figure 2: Volume of Advertisements, Web Sessions, and Transactions across Fall 2013 Television Season

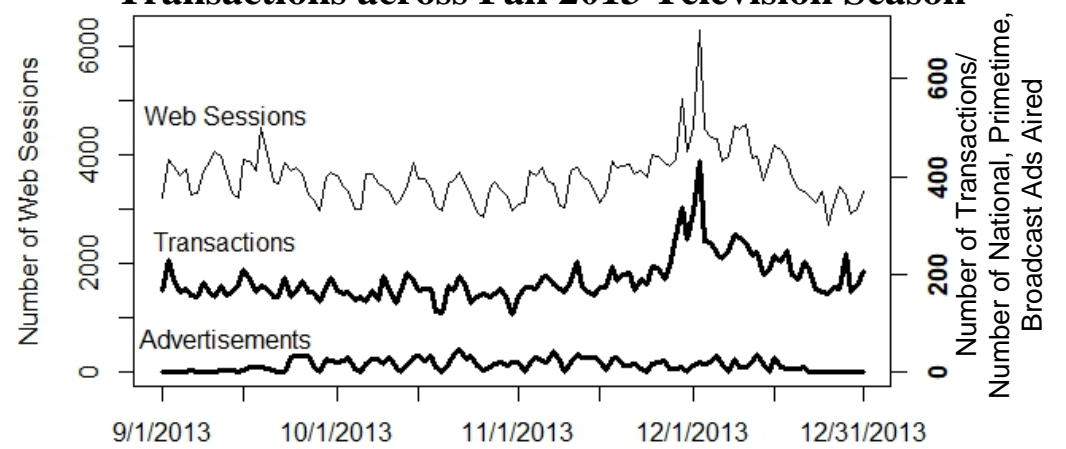

Note: The left y-axis is the number of web sessions on the retailers' websites. The right $y$-axis is the number of transactions on the retailers' websites and the number of national, primetime, broadcast ads aired by the retailers on recurring shows.

Figure 3: Transactions around the Advertisements' Airings

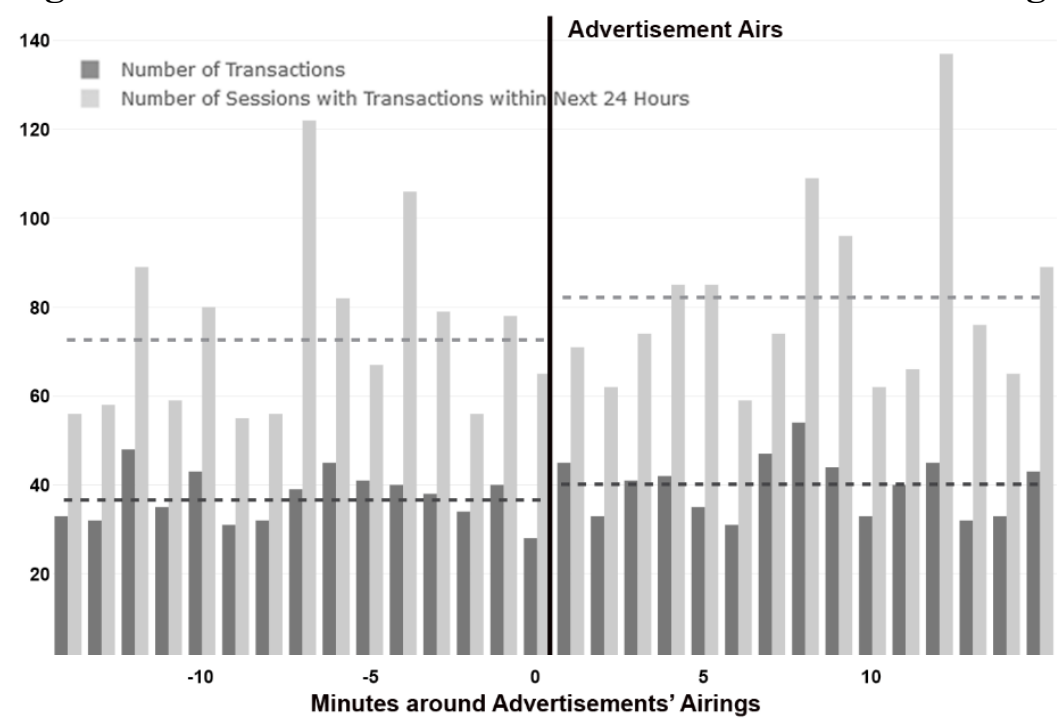

Note: Figure 2 shows the number of transactions summed across all retailers. The black dashed lines illustrate the mean number of transactions per minute in the fifteen-minute windows before and after the ads' airings. The gray dashed lines show the mean number of web sessions per minute that generated transactions within 24 hours from web sessions initiated in the fifteen-minute windows before and after the ads' airings. 
Figure 4: Relationship between Online Program Engagement and Online Shopping Activity
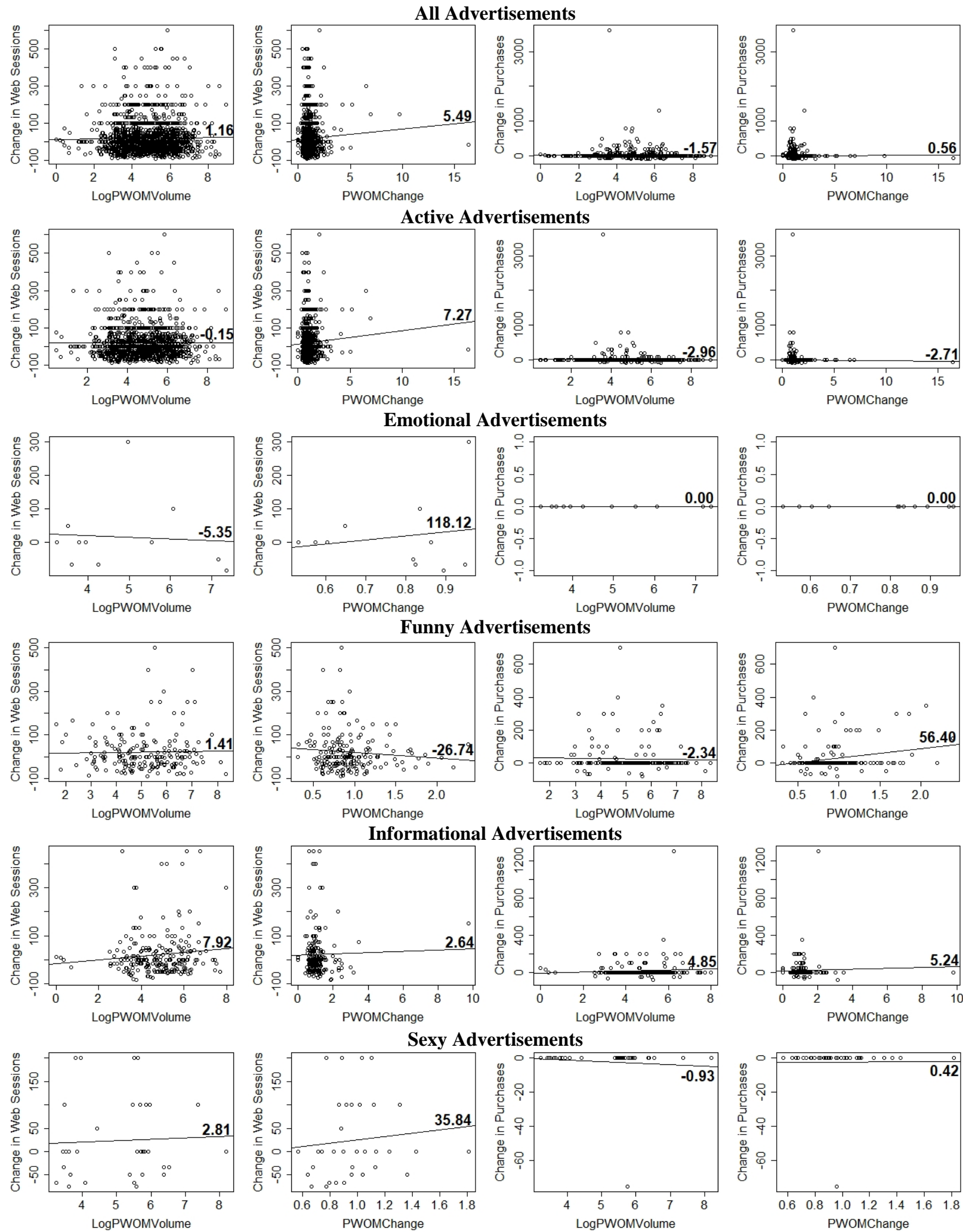

Note: Each figure shows the slope of the fitted line. See Table 5 for variable definitions and Table 4 for percentage change calculation. 
Figure 5: Estimated Effect Size of the Impact of Viewers' Online Program Engagement on Online Purchases across Ad Mood with PWOMVolume $_{i}$ at Median

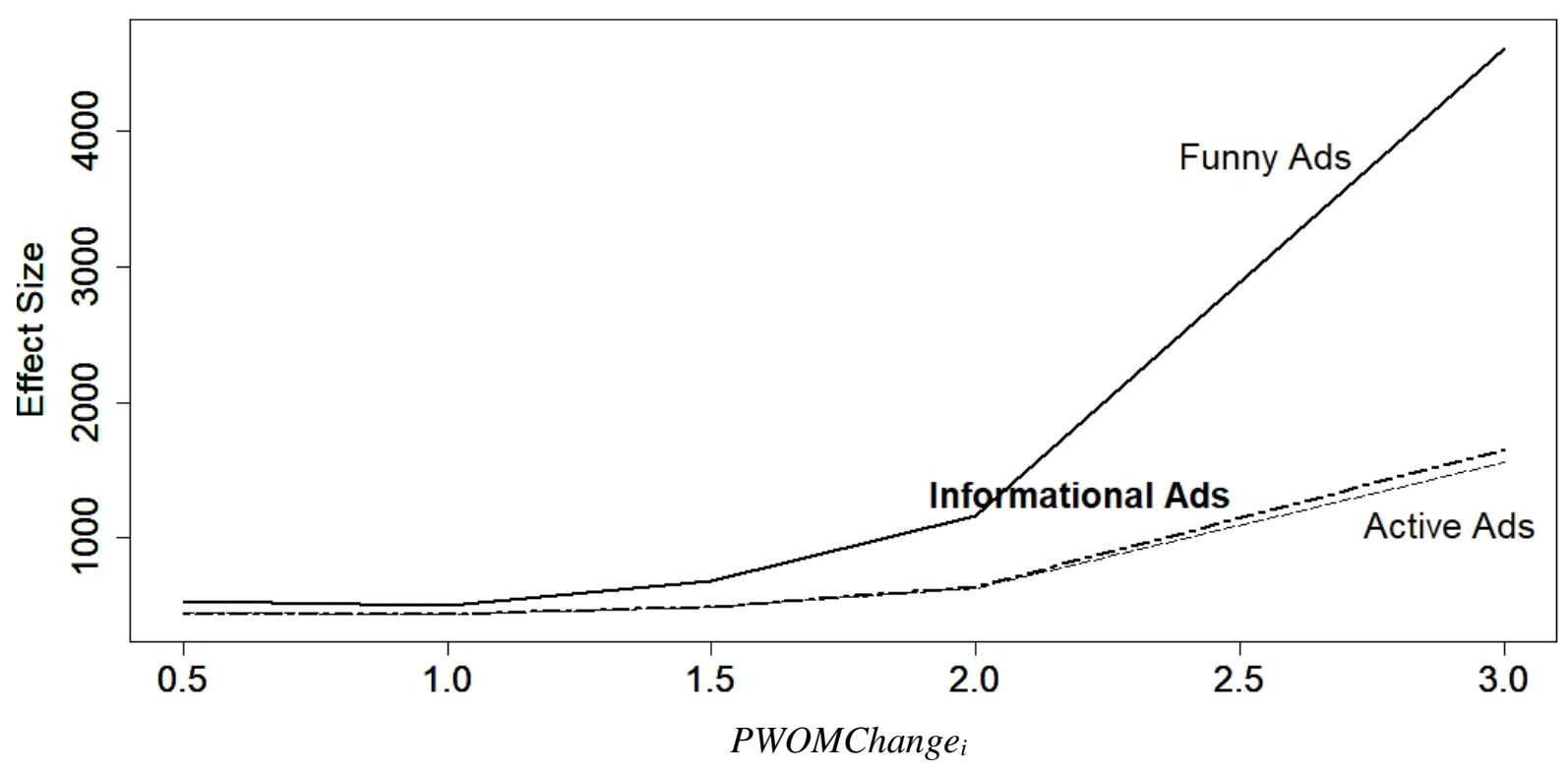

Note: Figure 5 shows the estimated effect size of the combined impact of the measures of online program engagement for those ad mood categories with at least one effect size in which the 95\% HPD interval excludes zero. This figure illustrates how the effect size changes as PWOMChange increases and with PWOMVolume $_{i}$ at its median value. See footnote 22 for calculation of combined effect, and see the note under Table 6 about effect size calculation. 